\title{
Optimal Monetary Policy in an Estimated DSGE Model of the Euro Area with Cross-Country Heterogeneity*
}

\author{
Eric Jondeau ${ }^{\mathrm{a}}$ and Jean-Guillaume Sahuc ${ }^{\mathrm{b}}$ \\ ${ }^{a}$ University of Lausanne and Swiss Finance Institute \\ ${ }^{\mathrm{b}}$ Banque de France and Audencia School of Management
}

This paper investigates the implications of cross-country heterogeneity within the euro area for the design of optimal monetary policy. We build an optimization-based multicountry model (MCM) describing the euro area in which differences between structural parameters across countries are allowed. Using Bayesian techniques, we estimate the MCM and its areawide counterpart (AWM). We then question which model is the most appropriate for monetary policy purposes. Several results emerge. First, using an AWM induces relatively large and significant welfare losses. Second, this is not the use of a rule based on aggregated variables that is costly in terms of welfare, but rather the use of a suboptimal forecasting model. Third, allowing for habit on consumption has important implications for the dynamics of models, but taking into account differences in price indexation has more drastic effects on welfare losses.

JEL Codes: C51, E52, F41.

${ }^{*}$ We thank S. Adjémian, J.-P. Benassy, M. Casares, P. Fève, M. Giannoni, P. Jacquinot, M. Juillard, J.-P. Laffargue, H. Le Bihan, A. Levin, J. Matheron, F. Mihoubi, E. Ortega, L. Patureau, the editor (F. Smets), and two anonymous referees for fruitful discussions and remarks. We have also benefited from comments by participants in seminars at the European Central Bank, workshops hosted by the Banque de France, CEPREMAP, Bank of Canada, UQAM, and the T2M conference. Financial support from the National Center of Competence in Research "Financial Valuation and Risk Management" is gratefully acknowledged. The National Centers of Competence in Research (NCCR) are a research instrument of the Swiss National Science Foundation. The views expressed in this paper are the responsibility of the authors and do not necessarily reflect those of the Banque de France. The usual disclaimer applies. Corresponding author: Sahuc: Banque de France, Economic and Financial Research Division, 31 rue Croix des Petits Champs, F-75049 Paris, France. E-mail: jean-guillaume.sahuc@banque-france.fr. 


\section{Introduction}

The Maastricht Treaty (article 105) states that the primary objective of the European Central Bank (ECB) is to maintain price stability within the European Monetary Union. Although the ECB may use a battery of economic indicators - including country-specific ones - in order to fulfill this primary objective, it makes decisions on the basis of aggregate developments, while national idiosyncrasies are left to the care of national governments. The consequences of such a constraint on the monetary policy of the euro area are obviously related to the extent and the nature of heterogeneity of countries within the area. Since the decisions have to be made on the basis of aggregate developments only, it may be argued that, since objectives are defined in terms of aggregate variables, an area-wide model (AWM) would be sufficient for capturing most characteristics of the euroarea economy. On the other hand, a multicountry model (MCM) may help capture the heterogeneity of countries and therefore offer valuable information about the state of the euro-area economy. Consequently, it would help define a more appropriate monetary policy rule. As a result, it is not clear a priori what type of forecasting model (multicountry or area-wide) should be used for implementing an optimal monetary policy.

To investigate the role devoted to country-specific information in the decision process regarding the Eurosystem, the standard approach to policy evaluation can be followed (see the contributions in Taylor 1999): the optimal policy rule is determined so as to minimize the expected value of an intertemporal loss function, under the constraint provided by a low-dimensional multicountry model of the euro area. Assuming that the monetary authority is exclusively interested in area-wide objectives, it is possible to compare the performance of two optimal reaction functions based on an MCM and an AWM, respectively. Such a comparison has already been performed in a few sets of contributions, revealing that the loss associated with the neglect of country-specific information might be large. ${ }^{1}$ However, in these studies, the underlying macroeconomic

\footnotetext{
${ }^{1}$ The literature includes De Grauwe (2000), De Grauwe and Piskorki (2001), Aksoy, De Grauwe, and Dewachter (2002), Angelini et al. (2002), and Monteforte and Siviero (2003), among others.
} 
models are not designed in an optimization-based framework. Consequently, the optimal monetary policy deduced from such models is subject to the Lucas critique, since it is based on reducedform, rather than structural, parameters. This is a serious limitation when the welfare resulting from an optimal policy rule has to be evaluated.

The objective of this paper is to reassess and generalize the preceding results in investigating how heterogeneity of agents across euro-area countries is likely to affect the optimal monetary policy using an optimization-based framework. More precisely, we measure the welfare cost of using an AWM instead of an MCM to evaluate the optimal monetary policy. The basic idea is that the MCM is designed to capture the cross-country heterogeneity and thus to describe more accurately the way monetary policy affects the economy. Consequently, a welfare-maximizing central bank may be able to implement a more efficient monetary policy, even if the policy rule is assumed to be based on aggregate variables only. An obvious shortcoming of the MCM is that its estimation is much more demanding, since it requires modeling the joint dynamics of several economies as well as the international transmission mechanisms. In addition, the MCM is likely to induce a large amount of countryspecific uncertainty, while an AWM may average these errors. Conversely, the estimation of an AWM is likely to induce an aggregation bias if structural parameters actually differ across countries. Such a bias has already been highlighted in the context of the Phillips curve (see Demertzis and Hughes Hallett 1998, Benigno and López-Salido 2006, or Altissimo, Mojon, and Zaffaroni 2007), but its consequences on the optimal monetary policy in a complete model have not been explored up to now.

In the class of dynamic stochastic general equilibrium (DSGE) models, several alternative models provide plausible frameworks to take heterogeneity into account. Our approach consists of designing a low-dimensional model that fits the data fairly well. The first reason for doing so is that in a simple structural model, the underlying mechanisms are easy to understand and the subsequent welfare analysis is transparent. Second, to measure the effect of crosscountry heterogeneity on monetary policy, we need to estimate the structural parameters of all the individual economies. As a consequence, a low-dimensional model is required to obtain consistent 
estimates. Estimation is based on Bayesian techniques, which seem to be the best way to determine an empirically realistic specification of the heterogeneity.

The model we consider resorts to the "new open-economy macroeconomics" literature, initiated by Obstfeld and Rogoff (1995). In addition to significant frictions in the form of nominal rigidities, other mechanisms are introduced: (i) cross-country differences in the structural parameters are allowed, since we are primarily interested in the effect of such heterogeneity on the design of the optimal monetary policy, (ii) perfect risk sharing and a home bias in preferences are incorporated in the model to deal with exchange rate indeterminacy, and (iii) cross-country correlations between shocks are introduced to capture co-movement in the joint dynamics of national conditions.

Following the strategy described above, we first estimate two models, mimicking the way the ECB forecasts macroeconomic developments within the Eurosystem. In the first one, we adopt an openeconomy framework and model the joint dynamics of the data for the major countries in the euro area (Germany, France, and Italy). In the second one, we model the dynamics of area-wide macroeconomic data. Our empirical evidence suggests that there exists some significant heterogeneity within the euro area, even among core countries. First, we obtain some significant differences between estimates of the structural parameters at the euro-area level and at the country level, suggesting an aggregation bias. But more importantly, we find that the main source of heterogeneity is the weak correlation between shocks across countries.

Then, we investigate how cross-country heterogeneity affects the design of optimal monetary policy within the euro area. We consider two alternative modeling approaches. In both of them, the central bank defines its preferences and its loss function at the area-wide level, and the reaction function is designed in terms of aggregate variables only. In the first approach the MCM, estimated using countryspecific data, is used for computing the loss function, while in the second approach the AWM, estimated using aggregated data, is used. Then, we evaluate the optimal monetary policy that maximizes the aggregate welfare, both under the AWM and the MCM, and we measure the welfare cost of using the AWM (suboptimal) forecasting model. We obtain that the welfare cost is quite significant, both 
statistically and economically. It appears to be related mainly to nominal rigidities rather than to real rigidities.

The remainder of the paper is organized as follows. In section 2, we describe the theoretical MCM. In section 3, we present the data and the estimates of the MCM and AWM. In section 4, we determine the optimal monetary policy under the two forecasting models and evaluate the welfare implications of using the (suboptimal) AWM model. Section 5 summarizes our main findings and concludes.

\section{Structure of the Stylized Multicountry Model}

The euro area is modeled as the aggregate of several economies. For each country, we formulate a small-size open-economy model, which is inspired by recent theoretical models derived from the "new openeconomy macroeconomics" literature. ${ }^{2}$ The model is enriched in several dimensions to offer a comprehensive framework that encompasses other previous contributions. In terms of dynamics, first, key modifications are the explicit incorporation of habit formation in the households' preferences and partial indexation in a price-setting framework à la Calvo (1983). These assumptions provide us with microfounded "hybrid" versions of the IS and Phillips curves. Second, contrary to most recent studies on DSGE models, we do not assume that preferences and technologies are the same across countries, since we are interested in measuring the effect of heterogeneity on the optimal monetary policy of the area. In addition, domestic and foreign shocks are allowed to be imperfectly correlated. Third, we resort to the perfect-risk-sharing assumption. Although this assumption is admittedly heroic in empirical work, it avoids assuming nonrational expectations of exchange rate, which has been shown to be an alternative way of dealing with nonstationarity. Finally, households are assumed to have a taste bias toward goods produced in their home country. Since preferences differ across countries, the price of consumption bundles will differ when expressed in

\footnotetext{
${ }^{2}$ See, among others, Monacelli (2001), Clarida, Galí, and Gertler (2002), Smets and Wouters (2002), Benigno and Benigno (2003), Devereux and Engel (2003), P. Benigno (2004), Corsetti and Pesenti (2005), and Galí and Monacelli (2005).
} 
a common currency. The real exchange rate thus deviates from purchasing power parity (PPP). ${ }^{3}$ This assumption is crucial, because it allows the perfect-risk-sharing equation to determine uniquely the dynamics of the terms of trade.

In order to lighten the notations, we assume that there are two countries in the euro area, denoted H (home) and F (foreign). Since commercial links are much stronger between countries within the area than with countries outside the area, we neglect trade with the rest of the world. The population of the euro area is a continuum of agents on the interval $[0,1]$. The population of country $\mathrm{H}$ belongs to $[0, n)$, while the foreign population belongs to $[n, 1]$. Therefore, $n$ is the relative measure of the home-country size in the euro area. An agent in the home country is indexed $h \in[0, n)$, while a foreign agent is indexed $f \in[n, 1]$. Variables in the home country are denoted $X_{t}$, while foreign variables are denoted $X_{t}^{*}$. The home economy produces a continuum of differentiated goods indexed on the interval $[0, n)$. Foreign goods (or, equivalently, goods produced in the rest of the area) are indexed on the interval $[n, 1]$. All goods are tradable.

\subsection{Households}

The home economy is populated by infinitively living households consuming Dixit-Stiglitz aggregates of domestic and imported goods. A home household $h$ owns a firm producing goods $h$ and receives dividends from it. We assume that households in a given country have the same preferences and endowments. Although there may be idiosyncratic shocks among households, we assume that households have access to complete markets for state-contingent claims, so that there is no heterogeneity among agents in a given country. Consequently, all households in the same country behave in the same manner, and then we consider the optimization problem of a representative household. The representative household in country $\mathrm{H}$ maximizes the following expected sequence of present and future utility flows

\footnotetext{
${ }^{3}$ An earlier contribution that introduced home-country bias in preferences is due to Warnock (2000).
} 
that depends positively on consumption $\left(C_{t}\right)$ and negatively on labor (hours worked, $\left.L_{t}\right):^{4}$

$\mathcal{U}_{t}=\mathbb{E}_{t} \sum_{k=0}^{\infty} \beta^{k} \varepsilon_{p, t+k}\left[\frac{1}{1-\sigma}\left(C_{t+k}-\gamma \mathcal{H}_{t+k}\right)^{1-\sigma}-\frac{1}{1+\varphi}\left(L_{t+k}\right)^{1+\varphi}\right]$,

subject to a series of real-period budget constraints:

$$
C_{t}+\frac{B_{t+1}}{\left(1+i_{t}\right) P_{t}}+\frac{T_{t}}{P_{t}}=\frac{W_{t} L_{t}}{P_{t}}+\frac{B_{t}}{P_{t}}+\frac{\Pi_{t}}{P_{t}},
$$

where $\mathbb{E}_{t}$ denotes the expectation operator conditional on the information set at time $t ; \beta$ is the intertemporal discount factor, with $0<\beta<1 ; \sigma$ is the inverse of the intertemporal elasticity of substitution of consumption; and $\varphi$ is the inverse of the elasticity of labor disutility with respect to hours worked. In addition, $W_{t}$ is the nominal wage income, $\Pi_{t}$ is the dividend received from home firms, $T_{t}$ represents nominal lump-sum government transfers, and $i_{t}$ is the nominal interest rate. $\varepsilon_{p, t}$ denotes a country-specific preference shock that affects the intertemporal substitution of all households in the same manner in the home economy. Preferences display external habit formation as in Abel (1990). The habit stock is supposed to equal the level of aggregate consumption in the previous period $\left(\mathcal{H}_{t}=C_{t-1}\right)$, and $\gamma$ represents the habit-persistence parameter, measuring the effect of past consumption on current utility $(0 \leq \gamma<1)$. Finally, we assume complete markets for statecontingent claims. Consequently, households can transfer wealth to the next period by holding $B_{t+1}$ units of the one-period nominal bond denominated in the domestic currency. ${ }^{5}$

\footnotetext{
${ }^{4}$ We abstract from money in this model since the central bank adjusts money supply to satisfy money demand with a simple feedback rule.

${ }^{5}$ More precisely, at date $t$, home households hold $B\left(s^{t+1}\right)=B_{t+1}$ units of the one-period bond denominated in home currency that pay 1 at date $t+1$ if state $s_{t+1}$ occurs and 0 otherwise, where $s^{t}=\left(s_{0}, \cdots, s_{t}\right)$ denotes the story of events up to date $t$. Foreign households hold $B_{t}^{*}\left(s^{t+1}\right)=B_{t+1}^{*}$ units of such bond. The price of this bond in home currency is denoted by $\Phi\left(s^{t}, s^{t+1}\right)=\Phi_{t, t+1}$. The price at date $t$ of the portfolio held by home households is thus given by $E_{t}\left[\Phi_{t, t+1} B_{t+1}\right]$. We define the one-period interest rate as $1+i_{t}=1 / E_{t}\left[\Phi_{t, t+1}\right]$.
} 
The maximization problem of the home household consists in maximizing equation (1) subject to constraint (2), yielding the optimal profile of consumption - holdings of domestic bond and labor supply. The first-order conditions imply ${ }^{6}$

$$
\begin{gathered}
\mathcal{U}_{C, t}=\varepsilon_{p, t}\left(C_{t}-\gamma \mathcal{H}_{t}\right)^{-\sigma}, \\
\left(1+i_{t}\right)^{-1}=\beta \mathbb{E}_{t}\left[\frac{\mathcal{U}_{C, t+1}}{\mathcal{U}_{C, t}} \frac{P_{t}}{P_{t+1}}\right], \\
\frac{\mathcal{U}_{L, t}}{\mathcal{U}_{C, t}}=\frac{W_{t}}{P_{t}},
\end{gathered}
$$

where $\mathcal{U}_{X, t}$ denotes the derivative of utility $\mathcal{U}$ with respect to variable $X$ at period $t$. Equation (3) defines the marginal utility of consumption. Equation (4) is the usual Euler equation for intertemporal consumption flows. It establishes that the ratio of marginal utility of future and current consumption is equal to the inverse of the real interest rate. Equation (5) is the condition for the optimal consumption-leisure arbitrage, implying that the marginal rate of substitution between consumption and labor is equated to the real wage.

\subsubsection{Composite Consumption Index}

The aggregate consumption index for home households and the corresponding consumption index for foreign households are defined by ${ }^{7}$

$$
C_{t}=\frac{\left(C_{H, t}\right)^{\omega}\left(C_{F, t}\right)^{1-\omega}}{\omega^{\omega}(1-\omega)^{1-\omega}} \text { and } C_{t}^{*}=\frac{\left(C_{H, t}^{*}\right)^{\omega^{*}}\left(C_{F, t}^{*}\right)^{1-\omega^{*}}}{\left(\omega^{*}\right)^{\omega^{*}}\left(1-\omega^{*}\right)^{1-\omega^{*}}},
$$

where $\omega$ and $\omega^{*}$ denote the share of home goods in the consumption of home and foreign households, respectively. $C_{H, t}$ (resp. $C_{F, t}$ )

\footnotetext{
Note that, since bonds are state-contingent, including bonds denominated in foreign currency would be redundant. For more details, see Chari, Kehoe, and McGrattan (2002).

${ }^{6}$ We abstract here from the optimal intratemporal allocations between domestic and foreign goods.

${ }^{7}$ As shown by Corsetti and Pesenti (2005), the Cobb-Douglas consumption index is a sufficient condition for the trade to be invariably balanced.
} 
is the subindex of consumption of imperfectly substitutable home (resp. foreign) goods, which is in turn given by the following CES aggregators:

$$
\begin{aligned}
C_{H, t} & =\left[\left(\frac{1}{n}\right)^{1 / \theta} \int_{0}^{n} C_{t}(h)^{\frac{\theta-1}{\theta}} \mathrm{d} h\right]^{\frac{\theta}{\theta-1}} \text { and } \\
C_{F, t} & =\left[\left(\frac{1}{1-n}\right)^{1 / \theta} \int_{n}^{1} C_{t}(f)^{\frac{\theta-1}{\theta}} \mathrm{d} f\right]^{\frac{\theta}{\theta-1}},
\end{aligned}
$$

where $C_{t}(h)$ (resp. $C_{t}(f)$ ) is consumption of the generic good $h$ (resp. $f$ ) produced in country $\mathrm{H}$ (resp. F). Parameter $\theta$ denotes the elasticity of substitution across goods produced within a given country. The corresponding consumption price indexes (CPIs) are given by

$$
P_{t}=\left(P_{H, t}\right)^{\omega}\left(P_{F, t}\right)^{1-\omega} \text { and } P_{t}^{*}=\left(P_{H, t}^{*}\right)^{\omega^{*}}\left(P_{F, t}^{*}\right)^{1-\omega^{*}} .
$$

Here, $P_{H, t}$ (resp. $P_{F, t}$ ) is the price subindex for home-produced (resp. foreign-produced) goods expressed in the home currency, defined as

$$
\begin{aligned}
P_{H, t} & =\left[\frac{1}{n} \int_{0}^{n} P_{H, t}(h)^{1-\theta} \mathrm{d} h\right]^{\frac{1}{1-\theta}} \text { and } \\
P_{F, t} & =\left[\frac{1}{1-n} \int_{n}^{1} P_{F, t}(f)^{1-\theta} \mathrm{d} f\right]^{\frac{1}{1-\theta}},
\end{aligned}
$$

where $P_{H, t}(h)$ (resp. $\left.P_{F, t}(f)\right)$ is the price in units of country $\mathrm{H}$ of a generic good $h$ (resp. $f$ ) produced in country $\mathrm{H}$ (resp. F).

We also assume that prices are set in the producer currency and that the law of one price holds. We then have $P_{H, t}(h)=P_{H, t}^{*}(h) S_{t}$ and $P_{F, t}(f)=P_{F, t}^{*}(f) S_{t}$, where $S_{t}$ is the nominal exchange rate expressed as units of domestic currency needed for one unit of foreign currency. ${ }^{8}$ Since we assume the same elasticity of substitution

${ }^{8}$ Although it has been investigated in a number of recent papers, we do not consider here the presence of imperfect exchange rate pass-through. A reason is that it is not likely to be an important feature across countries within the euro area. In addition, this feature is obviously irrelevant from the euro-area point of view. 
among goods in a given country, we also have $P_{H, t}=P_{H, t}^{*} S_{t}$ and $P_{F, t}=P_{F, t}^{*} S_{t}$. Yet, from the definition of the CPI, we obtain that

$$
P_{t}=P_{t}^{*} S_{t}\left(\frac{P_{H, t}}{P_{F, t}}\right)^{\omega-\omega^{*}} .
$$

Therefore, if we assume that there exists a home bias in preferences $\left(\omega \neq \omega^{*}\right)$, PPP does not necessarily hold; i.e., $P_{t} \neq P_{t}^{*} S_{t}$. We expect $\omega>\omega^{*}$, so that home households put a higher weight on home goods than foreign households.

\subsubsection{International Risk Sharing}

Under the assumption of complete markets, domestic and foreign households trade in state-contingent claims denominated in the home currency. This implies the following perfect-risk-sharing condition (Chari, Kehoe, and McGrattan 2002):

$$
Q_{t}=\kappa \frac{\mathcal{U}_{C}^{*}, t}{\mathcal{U}_{C, t}}
$$

where the real exchange rate, defined as $Q_{t} \equiv S_{t} P_{t}^{*} / P_{t}$, is proportional to the ratio of the marginal utility of consumption between the two countries. ${ }^{9}$ The assumption of international market completeness ensures that, in our model, the real exchange rate and consumption are stationary variables (see also G. Benigno 2004).

Since the real exchange rate deviates from PPP because of home bias in preferences, we also have

$$
Q_{t}=\left(\frac{S_{t} P_{H, t}^{*}}{P_{H, t}}\right)^{\omega^{*}}\left(\frac{S_{t} P_{F, t}^{*}}{P_{F, t}}\right)^{1-\omega^{*}}\left(\frac{P_{F, t}}{P_{H, t}}\right)^{\omega-\omega^{*}}=\left(\mathcal{T}_{t}\right)^{\omega-\omega^{*}}
$$

where $\mathcal{T}_{t}$ represents the home terms of trade, i.e., the relative price between foreign and home bundles of goods as perceived by the home resident. It is defined as ${ }^{10}$

$$
\mathcal{T}_{t}=\frac{P_{F, t}}{P_{H, t}}=\frac{S_{t} P_{F, t}^{*}}{P_{H, t}} .
$$

\footnotetext{
${ }^{9} \kappa=\left[S_{0} P_{0}^{*} \mathcal{U}_{C, 0}\right] /\left[P_{0} \mathcal{U}_{C^{*}, 0}^{*}\right]$ is a constant that depicts the initial condition.

${ }^{10}$ The foreign terms of trade are simply given by $\mathcal{T}_{t}^{*}=P_{H, t}^{*} / P_{F, t}^{*}=1 / \mathcal{T}_{t}$, because the law of one price holds.
} 
Using equations (3), (8), and (9), this definition implies the following:

$$
\left(\mathcal{T}_{t}\right)^{\omega-\omega^{*}}=\kappa \frac{\varepsilon_{p, t}^{*}\left(C_{t}-\gamma C_{t-1}\right)^{\sigma}}{\varepsilon_{p, t}\left(C_{t}^{*}-\gamma^{*} C_{t-1}^{*}\right)^{\sigma^{*}}} .
$$

Note that, when there is no home bias in preferences $\left(\omega=\omega^{*}\right)$, the perfect-risk-sharing assumption does not allow us to determine the terms of trade anymore.

Combining Euler equation (4) with the perfect-risk-sharing equation (8), we obtain the following dynamics for the real exchange rate and the terms of trade:

$$
\begin{aligned}
& \mathbb{E}_{t}\left[\frac{Q_{t+1}}{Q_{t}}\right]=\mathbb{E}_{t}\left[\frac{\mathcal{U}_{C}^{*}\left(C_{t+1}^{*}\right) \mathcal{U}_{C}\left(C_{t}\right)}{\mathcal{U}_{C}^{*}\left(C_{t}^{*}\right) \mathcal{U}_{C}\left(C_{t+1}\right)} \frac{P_{t}^{*} P_{t+1}}{P_{t} P_{t+1}^{*}}\right]=\frac{1+i_{t}}{1+i_{t}^{*}} \\
& \mathbb{E}_{t}\left[\frac{\mathcal{T}_{t+1}}{\mathcal{T}_{t}}\right]=\mathbb{E}_{t}\left[\frac{P_{F, t+1}^{*} P_{H, t}}{P_{H, t+1} P_{F, t}^{*}} \frac{1+i_{t}}{1+i_{t}^{*}}\right] .
\end{aligned}
$$

Equation (12) is the uncovered interest rate parity (UIP) condition, which states that the expected change in the exchange rate is exactly compensated by the real interest rate differential. It is worth emphasizing that the UIP condition is not an additional implication in the model, but rather a redundant relation.

\subsection{Firms}

There is a continuum of infinitely living and monopolistically competitive firms indexed by $h$ on the interval $[0, n)$ for the home country and by $f$ on the interval $[n, 1]$ for the foreign country. These firms produce differentiated goods that are bundled into homogeneous home and foreign goods by a constant returns to scale of the Dixit-Stiglitz form:

$$
\begin{aligned}
Y_{t} & =\left[\left(\frac{1}{n}\right)^{1 / \theta} \int_{0}^{n} Y_{t}(h)^{\frac{\theta-1}{\theta}} \mathrm{d} h\right]^{\frac{\theta}{\theta-1}} \text { and } \\
Y_{t}^{*} & =\left[\left(\frac{1}{1-n}\right)^{1 / \theta} \int_{n}^{1} Y_{t}^{*}(f)^{\frac{\theta-1}{\theta}} \mathrm{d} f\right]^{\frac{\theta}{\theta-1}} .
\end{aligned}
$$


The production technology of the representative home firm $h$ combines labor as primary input and a country-specific productivity shock:

$$
Y_{t}(h)=\varepsilon_{a, t} L_{t}(h) .
$$

Output is normalized by population size, so that it is expressed in per capita terms. We thus deduce that total home labor demand is given by

$$
L_{t}=\int_{0}^{n} L_{t}(h) \mathrm{d} h=\frac{\Delta_{t} Y_{t}}{\varepsilon_{a, t}}
$$

where $\Delta_{t}=\int_{0}^{n} \frac{Y_{t}(h)}{Y_{t}} \mathrm{~d} h$ represents the dispersion of production across firms in the home economy.

Since input markets are perfectly competitive and country specific, the standard static first-order condition for cost minimization implies that all domestic firms have identical real marginal cost, $M C_{t}$, given by

$$
M C_{t}=\frac{1}{(1+\vartheta)} \frac{W_{t}}{P_{H, t} \varepsilon_{a, t}},
$$

where $\vartheta$ is a subsidy for output that offsets the effect of imperfect competition in goods markets on the steady-state level of output $(0 \leq \vartheta<1)$.

A firm's price-setting decision is modeled through a modified version of Calvo's (1983) staggering mechanism. In addition to the baseline mechanism, we allow for the possibility that firms that do not optimally set their prices may nonetheless adjust them to keep up with the previous-period increase in the general price level (see Sbordone 2003 and Christiano, Eichenbaum, and Evans 2005 for details concerning this assumption). In each period, a firm faces a constant probability, $1-\alpha$, of being able to reoptimize its price and chooses the new price $\tilde{P}_{H, t}(h)$ that maximizes the expected discounted sum of profits

$$
\mathbb{E}_{t} \sum_{k=0}^{\infty} \alpha^{k} \Upsilon_{t, t+k}\left[\frac{\tilde{P}_{H, t}(h) \Psi_{t, t+k}^{H}}{P_{H, t+k}}-M C_{t+k}\right] Y_{t+k}(h),
$$


subject to the sequence of demand equations

$$
Y_{t+k}(h)=\left(\frac{\tilde{P}_{H, t}(h) \Psi_{t, t+k}^{H}}{P_{H, t+k}}\right)^{-\theta} Y_{t+k},
$$

where $\Upsilon_{t, t+k}=\beta^{k} \mathcal{U}_{C}\left(C_{t+k}\right) / \mathcal{U}_{C}\left(C_{t}\right)$ is the discount factor between time $t$ and $t+k$, and

$$
\Psi_{t, t+k}^{H}= \begin{cases}\prod_{\nu=0}^{k-1}\left(\bar{\pi}_{H}\right)^{1-\xi}\left(\pi_{H, t+v}\right)^{\xi} & k>0 \\ 1 & k=0\end{cases}
$$

where $\bar{\pi}_{H}$ is the domestic trend inflation and the coefficient $\xi \in[0,1]$ indicates the degree of indexation to past prices during the periods in which the firm is not allowed to reoptimize. $\Psi_{t, t+k}^{H}$ is a correcting term that accounts for the fact that if the firm $h$ does not reoptimize its price, it updates its price according to the rule

$$
P_{H, t}(h)=\left(\bar{\pi}_{H}\right)^{1-\xi}\left(\pi_{H, t-1}\right)^{\xi} P_{H, t-1}(h) .
$$

Consequently, the first-order condition associated with the profit maximization implies that firms set their price equal to the discounted stream of expected future real marginal costs:

$$
\begin{aligned}
& \mathbb{E}_{t} \sum_{k=0}^{\infty} \alpha^{k} \Upsilon_{t, t+k}\left[\left(\bar{\pi}_{H}\right)^{(1-\xi) k}\left(\frac{P_{H, t+k-1}}{P_{H, t-1}}\right)^{\xi} \frac{\tilde{P}_{H, t}(h)}{P_{H, t+k}}-\frac{\theta}{\theta-1} M C_{t+k}\right] \\
& \quad \times Y_{t+k}(h)=0 .
\end{aligned}
$$

If flexible prices is assumed $(\alpha=0)$, this expression gives the optimal relative price $\tilde{P}_{H, t}(h) / P_{H, t}=\mu M C_{t}$, where $\mu \equiv \theta /(\theta-1)$ is the optimal markup in a flexible-price economy. As there are no firm-specific shocks in this economy, all firms that are allowed to reoptimize their price at date $t$ select the same optimal price $\tilde{P}_{H, t}(h)=\tilde{P}_{H, t}, \forall h$.

Staggered price setting under partial indexation implies the following expression for the evolution of the domestic price index:

$$
P_{H, t}=\left[\alpha\left(\left(\bar{\pi}_{H}\right)^{1-\xi}\left(\pi_{H, t-1}\right)^{\xi} P_{H, t-1}\right)^{1-\theta}+(1-\alpha)\left(\tilde{P}_{H, t}\right)^{1-\theta}\right]^{\frac{1}{1-\theta}} .
$$


The price-setting problem solved by firms in the foreign country is similar and leads to an optimal rule analogous to equation (21). However, we allow foreign structural parameters $\left(\alpha^{*}, \xi^{*}\right)$ and country-specific shocks $\left(\varepsilon_{a, t}^{*}\right)$ to differ from their home-country counterparts.

\subsection{Market-Clearing Conditions}

Demands for goods are given by the subindex of consumption (7); the allocation of demand across each of the goods produced within a given country for consumers $H, F$ is given by

$$
\begin{aligned}
C_{t}(h) & =\frac{1}{n}\left(\frac{P_{H, t}(h)}{P_{H, t}}\right)^{-\theta} C_{H, t} \text { and } C_{t}^{*}(h)=\frac{1}{n}\left(\frac{P_{H, t}^{*}(h)}{P_{H, t}^{*}}\right)^{-\theta} C_{H, t}^{*}, \\
C_{t}(f) & =\frac{1}{1-n}\left(\frac{P_{F, t}(f)}{P_{F, t}}\right)^{-\theta} C_{F, t} \quad \text { and } \\
C_{t}^{*}(f) & =\frac{1}{1-n}\left(\frac{P_{F, t}^{*}(f)}{P_{F, t}^{*}}\right)^{-\theta} C_{F, t}^{*} .
\end{aligned}
$$

The consumption aggregator (6) implies that home and foreign demands for composite home and foreign goods are given by

$$
\begin{aligned}
C_{H, t} & =\omega\left(\frac{P_{t}}{P_{H, t}}\right) C_{t} \quad \text { and } \quad C_{H, t}^{*}=\omega^{*}\left(\frac{P_{t}^{*}}{P_{H, t}^{*}}\right) C_{t}^{*}, \\
C_{F, t} & =(1-\omega)\left(\frac{P_{t}}{P_{F, t}}\right) C_{t} \quad \text { and } \quad C_{F, t}^{*}=\left(1-\omega^{*}\right)\left(\frac{P_{t}^{*}}{P_{F, t}^{*}}\right) C_{t}^{*} .
\end{aligned}
$$

Then, goods market clearing in the home and foreign countries implies

$$
\begin{aligned}
Y_{t}(h) & =n C_{t}(h)+(1-n) C_{t}^{*}(h) \\
& =\left(\frac{P_{H, t}(h)}{P_{H, t}}\right)^{-\theta}\left(\frac{P_{t}}{P_{H, t}}\right)\left(\omega C_{t}+\mathcal{T}_{t}^{\omega-\omega^{*}} \frac{1-n}{n} \omega^{*} C_{t}^{*}\right)
\end{aligned}
$$


and

$$
\begin{aligned}
Y_{t}^{*}(f) & =n C_{t}(f)+(1-n) C_{t}^{*}(f) \\
& =\left(\frac{P_{F, t}(f)}{P_{F, t}}\right)^{-\theta}\left(\frac{P_{t}}{P_{F, t}}\right)\left(\frac{n}{1-n}(1-\omega) C_{t}+\left(1-\omega^{*}\right) \mathcal{T}_{t}^{\omega-\omega^{*}} C_{t}^{*}\right),
\end{aligned}
$$

so that aggregate outputs in home and foreign goods are

$$
Y_{t}=\omega\left(\mathcal{T}_{t}\right)^{1-\omega} C_{t}+\frac{1-n}{n} \omega^{*}\left(\mathcal{T}_{t}\right)^{1-\omega^{*}} C_{t}^{*}
$$

and

$$
Y_{t}^{*}=(1-\omega)\left(\mathcal{T}_{t}\right)^{-\omega} \frac{n}{1-n} C_{t}+\left(1-\omega^{*}\right)\left(\mathcal{T}_{t}\right)^{-\omega^{*}} C_{t}^{*} .
$$

Together with equation (10), these relations show that aggregate output only depends on home and foreign consumptions and preference shocks.

\subsection{Log-Linear Equilibrium}

In order to estimate the model, we log-linearize it around the steady state. We also close the model by specifying a fairly simple monetary policy rule for each country, in which the short-term nominal interest rate responds to lagged interest rate as well as to deviations of inflation to its steady-state value and deviations of domestic aggregate output to its flexible-price equilibrium (or natural) value. This specification includes an additional monetary policy shock. Notice that, since the historical policy rule has not been necessarily optimal, the parameters of the reaction function cannot be viewed as structural ones. Consequently, we adopt for the moment a widely accepted specification, in order to estimate structural parameters reflecting the behavior of private agents. ${ }^{11}$ Finally, we need to specify the dynamics of the shocks. We assume that the preference, productivity, and monetary policy shocks follow AR(1) processes,

\footnotetext{
${ }^{11}$ See Dieppe, Küster, and McAdam (2005) for a comparison of several policy rules using an AWM.
} 
with autoregressive parameters denoted $\rho_{p}, \rho_{a}$, and $\rho_{i}$ and standard deviations denoted $\sigma_{p}, \sigma_{a}$, and $\sigma_{i}$, respectively.

The resulting system, expressed in percentage deviation around the steady state, is presented in appendix 1. Details of the construction of the flexible-price output are provided in appendix 2. The determination of the optimal monetary policy consistent with our structural model is performed in section 4 .

In the case of an area with more than two countries, the broad structure of the model remains essentially unchanged. The major change is that, in an $N$-country model, international transmission mechanisms pass through $(N-1)$ independent terms of trade. Consequently, since the Phillips curve depends on the terms of trade through movements in real marginal cost, inflation dynamics is affected by demand conditions in all countries. Moreover, domestic consumption is affected by the average of real interest rates prevailing in all countries of the area.

\section{Estimation}

We now concentrate on the two models that we will use to evaluate the optimal monetary policy rules: (i) an MCM that incorporates information on individual countries, allowing model parameters to differ from one country to another, and (ii) an AWM that implicitly assumes that the heterogeneity of behaviors and the asymmetry of shocks across countries can be neglected in the design of monetary policy. $^{12}$

Models used for policy analysis must naturally make quantitative predictions that can match observed regularities in the data. In this way, our small DSGE models search to match, in broad terms, the relationship among consumption (or output), inflation, and interest rates. But we do not explore the details of our model's fit to the data in this research. A technical appendix (available from the authors upon request) gives all the details concerning the empirical performance of the models and shows that both the MCM and the AWM

\footnotetext{
${ }^{12}$ For the AWM, we resort to the closed-economy version of the model described above, estimated over aggregated data of the euro area.
} 
are able to reproduce most dynamics of the data, although the data do not support all the restrictions imposed by the DSGE. ${ }^{13}$

It is clear that introducing additional mechanisms would enrich the model and substantially improve its fit. Such an extension would be crucial especially if the model was to be used for implementing policy applications (alternative policy scenarios, forecasting, etc.). In our context, we emphasize the ability of our models to provide some evidence on the consequences of heterogeneity for optimal monetary policy. As we will show in the next section, even within our simple framework, we obtain that the use of an AWM induces relatively large and significant welfare losses. The omitted heterogeneity is actually incorporated in shocks that do not play a great role in the welfare measure (only the preference shocks enter the welfare measure). Since we obtain a large gap between the two welfare measures even when not all the sources of heterogeneity are taken into account, adding additional sources would result in even higher welfare losses. In section 4.4, we discuss some alternative modeling specifications.

Estimation is performed using Bayesian techniques. ${ }^{14}$ The dynamical systems are cast in a state-space representation for the set of observable variables. The Kalman filter is then used to evaluate the likelihood of the observed variables and form the posterior distribution of the structural parameters by combining the likelihood function with a joint density characterizing some prior beliefs. Given the specification of the model, the posterior distribution cannot be recovered analytically but can be evaluated numerically, using a Markov-Chain Monte Carlo (MCMC) sampling approach. More specifically, we rely on the Metropolis-Hastings (MH) algorithm to obtain random draws from the posterior distribution of the parameters. ${ }^{15}$

\footnotetext{
${ }^{13}$ In the technical appendix, we first compare the posterior distributions of the DSGE and VAR models (see Geweke 1999); then we compare the DSGE-based cross-covariances (or autocorrelations) and/or impulse-response functions with those obtained from a VAR model.

${ }^{14}$ The Bayesian strategy has been proposed by, among others, Schorfheide (2003), Smets and Wouters (2003), and Fernandez-Villaverde and Rubio-Ramirez (2004).

${ }^{15}$ We simulate a sample of 200,000 random draws. The first 50,000 observations are discarded to eliminate any dependence on the initial values. The mode and the Hessian of the posterior distribution evaluated at the mode are used to initialize the $\mathrm{MH}$ algorithm.
} 


\subsection{Data}

The data are drawn from OECD's Business Sector Database for individual countries. The sample period runs from 1970:Q1 to 1998:Q4 at a quarterly frequency. We suppose that the euro area is represented by the three largest countries of the area (Germany, France, and Italy), which cover some 70 percent of the area-wide GDP. The MCM is then estimated for these three countries, while the AWM is estimated on the weighted average of series pertaining to the three countries under study.

The estimation of the model is based ultimately on three key macroeconomic variables for each country: real consumption, the inflation rate, and the nominal short-term interest rate. Neither the terms of trade nor the real marginal cost are necessary for the estimation of the model, since they are defined as exact functions of the other macroeconomic variables. Consumption is defined as real consumption expenditures, linearly detrended. We measure inflation as the annualized quarterly percent change in the implicit GDP deflator. The interest rate is the three-month money-market rate. Figure 1 displays the historical path of the various series under consideration for each country or area. In the case of the euro area, we also plot the series extracted from the AWM database provided by Fagan, Henry, and Mestre (2005). We first notice that the two data sets for the euro area look very similar. We also observe a downward trend in inflation and interest rate, which mainly corresponds to the convergence process of economic conditions within the euro area. The structural model presented above is clearly not designed to capture such an empirical feature. Therefore, inflation and the nominal interest rate are detrended by the same quadratic trend in inflation. ${ }^{16}$

\subsection{Prior Distribution and Calibrated Parameters}

In the definition of the prior distributions, we followed the now standard procedure, assuming a beta distribution for parameters bounded between zero and one, a uniform distribution for standard

\footnotetext{
${ }^{16} \mathrm{We}$ also examined if the estimates are modified when consumption is detrended using the regression on a quadratic time trend or a Hodrick-Prescott filter. The results were not altered in any significant way.
} 
Figure 1. Data

A. AWM - Detrended Consumption

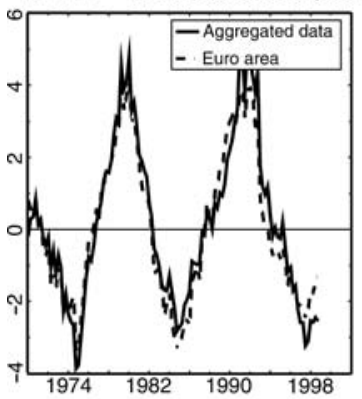

D. MCM - Detrended Consumption

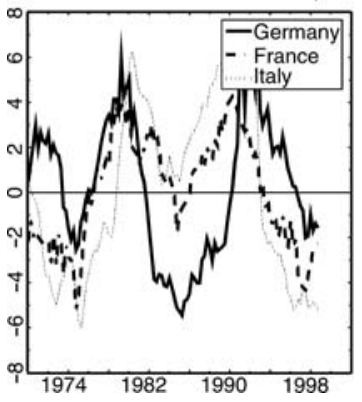

B. AWM - Inflation
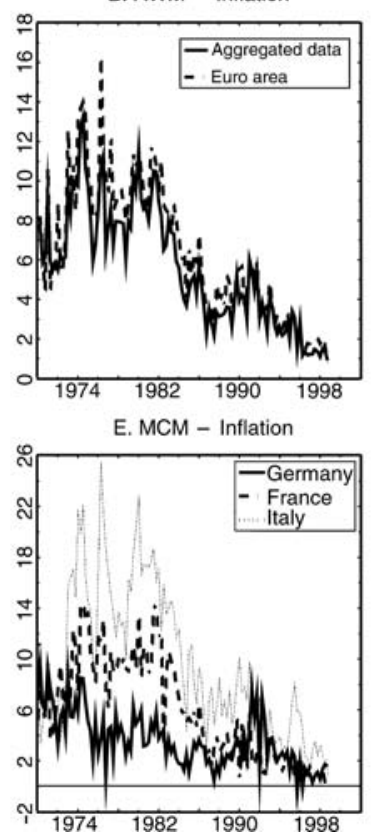

C. AWM - Interest rate
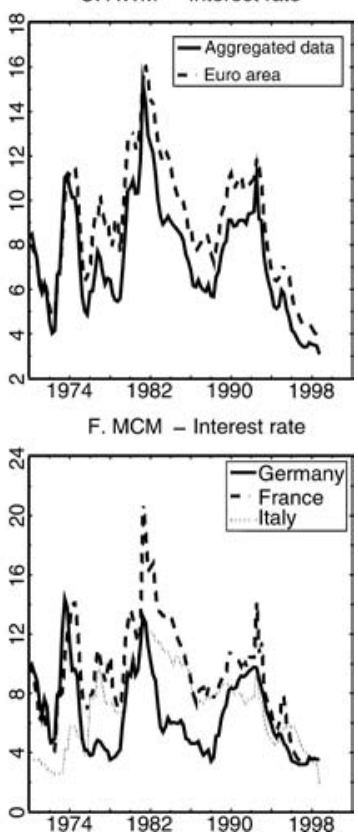

deviations of shocks, and a normal distribution for the remaining parameters. The main characteristics of the prior distributions are reported in table 1 . In most cases, distribution parameters are the same as in Smets and Wouters (2003) for the euro area, but we also incorporate some information drawn from Onatski and Williams (2004)..$^{17}$

While the shocks in a given country are assumed to be uncorrelated, we allow a nonzero correlation between a given shock in two countries. We thus denote $\delta_{p}, \delta_{a}$, and $\delta_{i}$ the correlations between domestic and foreign preference shocks, productivity shocks, and monetary policy shocks, respectively. Correlations across countries are assumed to follow a normal distribution, with a mean of 0.2 and

${ }^{17}$ Onatski and Williams (2004) provide an interesting investigation of some shortcomings of the standard Bayesian approach in the context of DSGE models. In particular, they put forward that parameter estimates are very sensitive to the way priors are introduced. We took advantage of some of their results. 
Table 1. Prior Distribution for the Parameters

\begin{tabular}{|l|c|c|c|c|}
\hline & & Type & Mean & Std. Error \\
\hline Consumption Habit & $\gamma$ & Beta & 0.700 & 0.100 \\
Consumption Elast. of Subst. & $\sigma$ & Normal & 2.000 & 0.250 \\
Labor Disutility & $\varphi$ & Normal & 2.000 & 0.250 \\
Price Indexation & $\xi$ & Beta & 0.700 & 0.100 \\
Calvo Probability & $\alpha$ & Beta & 0.700 & 0.100 \\
PR Lagged Interest Rate & $\psi_{i}$ & Beta & 0.700 & 0.100 \\
PR Inflation & $\psi_{\pi}$ & Normal & 1.500 & 0.100 \\
PR Output Gap & $\psi_{y}$ & Normal & 0.500 & 0.100 \\
Serial Corr. Preference Shock & $\rho_{p}$ & Beta & 0.600 & 0.100 \\
Serial Corr. Productivity Shock & $\rho_{a}$ & Beta & 0.600 & 0.100 \\
Serial Corr. Mon. Policy Shock & $\rho_{i}$ & Beta & 0.600 & 0.100 \\
Vol. Preference Shock & $\sigma_{p}$ & Uniform & 0.000 & 2.000 \\
Vol. Productivity Shock & $\sigma_{a}$ & Uniform & 0.000 & 2.000 \\
Vol. Mon. Policy Shock & $\sigma_{i}$ & Uniform & 0.000 & 2.000 \\
Cross-Corr. Preference Shocks & $\delta_{p}$ & Normal & 0.200 & 0.100 \\
Cross-Corr. Productivity Shocks & $\delta_{a}$ & Normal & 0.200 & 0.100 \\
Cross-Corr. Mon. Policy Shocks & $\delta_{i}$ & Normal & 0.200 & 0.100 \\
\hline
\end{tabular}

a standard error of 0.1 . We use the same priors for all countries and the euro area in turn.

Finally, we imposed dogmatic priors over the discount factor $\beta$ and the elasticity of substitution across goods produced in a given country, $\theta$. The values we use $(\beta=0.99$ and $\theta=10)$ are conventional in the literature. The consumption/output ratio $s$ is set equal to 0.57 for all countries. The selection of the parameters of home bias in preferences $(\omega)$ is done by using the trade flows statistics provided by the International Monetary Fund's Direction of Trade Statistics database. We first calculate the relative share of each country in the imports of the other countries. We then deduce the renormalized weights to be consistent with our assumption that the three countries under study cover the whole external trade of each other. We therefore set these parameters as follows, in order to reflect the weight of each country in the external trade of the others: 
the weights of German, French, and Italian goods in the consumption of German households are $(0.8 ; 0.11 ; 0.09)$. For French and Italian households, the weights are $(0.13 ; 0.8 ; 0.07)$ and $(0.13 ; 0.07 ; 0.8)$, respectively. We checked that marginally altering these values would not change significantly our results.

\subsection{Parameter Estimates}

\subsubsection{Results for the MCM}

The joint dynamics of the whole system is estimated simultaneously for Germany, France, and Italy. Table 2 provides two sets of information regarding parameter estimates. The first set reports the posterior mode of parameters, which is obtained directly by maximizing the log of the posterior distribution with respect to parameters. The second set contains the 5th, 50th (labeled "Median"), and 95th percentiles of the posterior distribution of parameters. The posterior distribution of some parameters (namely, $\sigma, \varphi$, and $\psi_{\pi}$ ) is rather close to the prior distribution. This suggests that these parameters do not strongly affect the likelihood and translates to the rather large associated standard deviations.

As regards the behavior of households, our estimates of the consumption elasticity of substitution $(\sigma)$ range between 1.5 and 2, while the inverse of the elasticity of labor disutility $(\varphi)$ is close to 2. Although we select the same priors for all countries, we obtain significant differences for the habit-persistence parameter $\gamma$. This parameter is estimated to be medium in Germany (0.63) and France (0.69), and large in Italy (0.78). Using the usual 5 percent significance level, we reject the null hypothesis that the three parameters are equal across countries, suggesting that there is some heterogeneity in structural parameters across countries. Turning to the behavior of firms, we obtain some disparity in the parameters of price indexation $\xi$, which range between 0.28 for Germany and 0.43 for Italy, although the difference does not turn out to be significant. The Calvo probabilities $\alpha$ are estimated around 0.82, suggesting that the average duration of price contracts is less than six quarters. Reaction-function parameters display similar patterns across countries. The long-run reactions of short-term interest rate to inflation and output gap are close to 1.5 and 0.5 , respectively, in the three countries. The interest-rate-smoothing parameter $\psi_{i}$ is about 0.87 . 


\section{Table 2. Parameter Estimates for the MCM}

\begin{tabular}{|c|c|c|c|c|c|c|}
\hline & \multicolumn{5}{|c|}{ Germany } \\
\hline & & Mode & Std. Dev. & $5 \%$ & Median & $95 \%$ \\
\hline Consumption Habit & $\gamma$ & 0.630 & 0.050 & 0.553 & 0.632 & 0.714 \\
\hline $\begin{array}{l}\text { Consumption Elasticity of } \\
\text { Substitution }\end{array}$ & $\sigma$ & 1.542 & 0.232 & 1.162 & 1.533 & 1.922 \\
\hline Labor Disutility & $\varphi$ & 1.934 & 0.253 & 1.522 & 1.929 & 2.349 \\
\hline Price Indexation & $\xi$ & 0.290 & 0.078 & 0.157 & 0.283 & 0.406 \\
\hline Calvo Probability & $\alpha$ & 0.839 & 0.019 & 0.809 & 0.840 & 0.869 \\
\hline $\begin{array}{l}\text { Policy Rule: Lagged Interest } \\
\text { Rate }\end{array}$ & $\psi_{i}$ & 0.871 & 0.020 & 0.841 & 0.873 & 0.901 \\
\hline Policy Rule: Inflation & $\psi_{\pi}$ & 1.507 & 0.100 & 1.340 & 1.510 & 1.666 \\
\hline Policy Rule: Output Gap & $\psi_{y}$ & 0.458 & 0.104 & 0.288 & 0.462 & 0.627 \\
\hline Serial Corr. Preference Shock & $\rho_{p}$ & 0.640 & 0.065 & 0.531 & 0.643 & 0.741 \\
\hline $\begin{array}{l}\text { Serial Corr. Productivity } \\
\text { Shock }\end{array}$ & $\rho_{a}$ & 0.740 & 0.067 & 0.635 & 0.741 & 0.854 \\
\hline $\begin{array}{l}\text { Serial Corr. Monetary Policy } \\
\text { Shock }\end{array}$ & $\rho_{i}$ & 0.506 & 0.067 & 0.395 & 0.508 & 0.617 \\
\hline Vol. Preference Shock & $\sigma_{p}$ & 0.048 & 0.008 & 0.035 & 0.047 & 0.061 \\
\hline Vol. Productivity Shock & $\sigma_{a}$ & 0.037 & 0.006 & 0.026 & 0.036 & 0.047 \\
\hline Vol. Monetary Policy Shock & $\sigma_{i}$ & 0.244 & 0.020 & 0.211 & 0.243 & 0.276 \\
\hline $\begin{array}{l}\text { Cross-Correlations } \\
\text { across Countries }\end{array}$ & & Mode & Std. Dev. & $5 \%$ & Median & $95 \%$ \\
\hline Preference Shock $-1 / 2$ & $\delta_{p 12}$ & 0.311 & 0.063 & 0.201 & 0.313 & 0.410 \\
\hline Preference Shock $-1 / 3$ & $\delta_{p 13}$ & 0.166 & 0.067 & 0.059 & 0.168 & 0.273 \\
\hline Preference Shock $-2 / 3$ & $\delta_{p 23}$ & 0.279 & 0.071 & 0.166 & 0.279 & 0.397 \\
\hline Productivity Shock $-1 / 2$ & $\delta_{a 12}$ & 0.194 & 0.067 & 0.077 & 0.196 & 0.300 \\
\hline Productivity Shock $-1 / 3$ & $\delta_{a 13}$ & -0.032 & 0.076 & -0.156 & -0.032 & 0.096 \\
\hline Productivity Shock $-2 / 3$ & $\delta_{a 23}$ & 0.135 & 0.075 & 0.018 & 0.138 & 0.258 \\
\hline Monetary Policy Shock $-1 / 2$ & $\delta_{i 12}$ & 0.198 & 0.070 & 0.087 & 0.200 & 0.317 \\
\hline Monetary Policy Shock $-1 / 3$ & $\delta_{i 13}$ & 0.124 & 0.066 & 0.016 & 0.127 & 0.229 \\
\hline Monetary Policy Shock $-2 / 3$ & $\delta_{i 23}$ & 0.239 & 0.069 & 0.132 & 0.237 & 0.355 \\
\hline
\end{tabular}

(Continued)

The standard deviations of the preference and productivity shocks are very close for the three countries, although they are smaller than the area-wide counterparts. In contrast, some large differences in the variability of the monetary policy shock are found. While the volatility is low in Germany and Italy (around 0.24 percent), it is large in France (at 0.42 percent). This result may be related to some aspects of the French monetary policy that are not 
Table 2. (Continued)

\begin{tabular}{|l|c|c|c|c|c|c|c|c|c|}
\hline \multicolumn{7}{|c|}{ France } & \multicolumn{5}{c|}{ Italy } \\
\hline Mode & Std. Dev. & $\mathbf{5 \%}$ & Median & $\mathbf{9 5 \%}$ & Mode & Std. Dev. & $\mathbf{5 \%}$ & Median & $\mathbf{9 5 \%}$ \\
\hline 0.688 & 0.045 & 0.617 & $\mathbf{0 . 6 9 1}$ & 0.765 & 0.777 & 0.029 & 0.730 & $\mathbf{0 . 7 7 7}$ & 0.823 \\
1.851 & 0.226 & 1.482 & $\mathbf{1 . 8 5 1}$ & 2.228 & 2.009 & 0.218 & 1.656 & $\mathbf{2 . 0 0 9}$ & 2.373 \\
& & & & & & & & & \\
2.015 & 0.252 & 1.595 & $\mathbf{2 . 0 1 9}$ & 2.428 & 1.922 & 0.247 & 1.511 & $\mathbf{1 . 9 1 9}$ & 2.316 \\
0.324 & 0.083 & 0.191 & $\mathbf{0 . 3 1 8}$ & 0.455 & 0.436 & 0.102 & 0.257 & $\mathbf{0 . 4 2 8}$ & 0.593 \\
0.822 & 0.017 & 0.794 & $\mathbf{0 . 8 2 3}$ & 0.848 & 0.794 & 0.022 & 0.759 & $\mathbf{0 . 7 9 5}$ & 0.830 \\
0.820 & 0.027 & 0.778 & $\mathbf{0 . 8 2 2}$ & 0.864 & 0.906 & 0.014 & 0.885 & $\mathbf{0 . 9 0 8}$ & 0.929 \\
& & & & & & & & & \\
1.517 & 0.101 & 1.353 & $\mathbf{1 . 5 1 8}$ & 1.681 & 1.497 & 0.094 & 1.344 & $\mathbf{1 . 5 0 0}$ & 1.648 \\
0.482 & 0.102 & 0.314 & $\mathbf{0 . 4 8 0}$ & 0.645 & 0.522 & 0.091 & 0.375 & $\mathbf{0 . 5 2 2}$ & 0.670 \\
0.509 & 0.077 & 0.380 & $\mathbf{0 . 5 1 0}$ & 0.633 & 0.793 & 0.036 & 0.739 & $\mathbf{0 . 7 9 5}$ & 0.851 \\
0.660 & 0.075 & 0.536 & $\mathbf{0 . 6 6 1}$ & 0.780 & 0.854 & 0.035 & 0.796 & $\mathbf{0 . 8 5 5}$ & 0.911 \\
& & & & & & & & & \\
0.447 & 0.067 & 0.337 & $\mathbf{0 . 4 4 5}$ & 0.557 & 0.414 & 0.071 & 0.300 & $\mathbf{0 . 4 1 2}$ & 0.534 \\
& & & & & & & & & \\
0.063 & 0.010 & 0.047 & $\mathbf{0 . 0 6 2}$ & 0.078 & 0.055 & 0.008 & 0.043 & $\mathbf{0 . 0 5 4}$ & 0.068 \\
0.038 & 0.007 & 0.028 & $\mathbf{0 . 0 3 8}$ & 0.050 & 0.035 & 0.006 & 0.026 & $\mathbf{0 . 0 3 5}$ & 0.045 \\
0.426 & 0.034 & 0.372 & $\mathbf{0 . 4 2 3}$ & 0.482 & 0.228 & 0.021 & 0.196 & $\mathbf{0 . 2 2 6}$ & 0.261 \\
\hline
\end{tabular}

incorporated in the model, such as the implicit anchoring to the German monetary policy from 1983 on.

Concerning the serial correlation of shocks, the table reveals some significant differences across countries for the preference shock ( $\rho_{p}=0.51$ in France and 0.80 in Italy) and for the productivity shock $\left(\rho_{a}=0.66\right.$ in France and 0.86 in Italy). In contrast, the estimates of $\rho_{i}$ are all very close to 0.45 . Most cross-country correlations between shocks are significantly positive. Note, however, that shocks are far from being perfectly correlated across countries. This result is of importance, because it suggests that the asymmetry of shocks may be rather large across countries. It appears as the main source of heterogeneity within the euro area.

\subsubsection{Results for the AWM}

Table 3 reports the parameter estimates for the AWM model. As regards the behavior of households, our estimate of the inverse of the consumption elasticity of substitution $(\sigma)$ is equal to 2.08, 


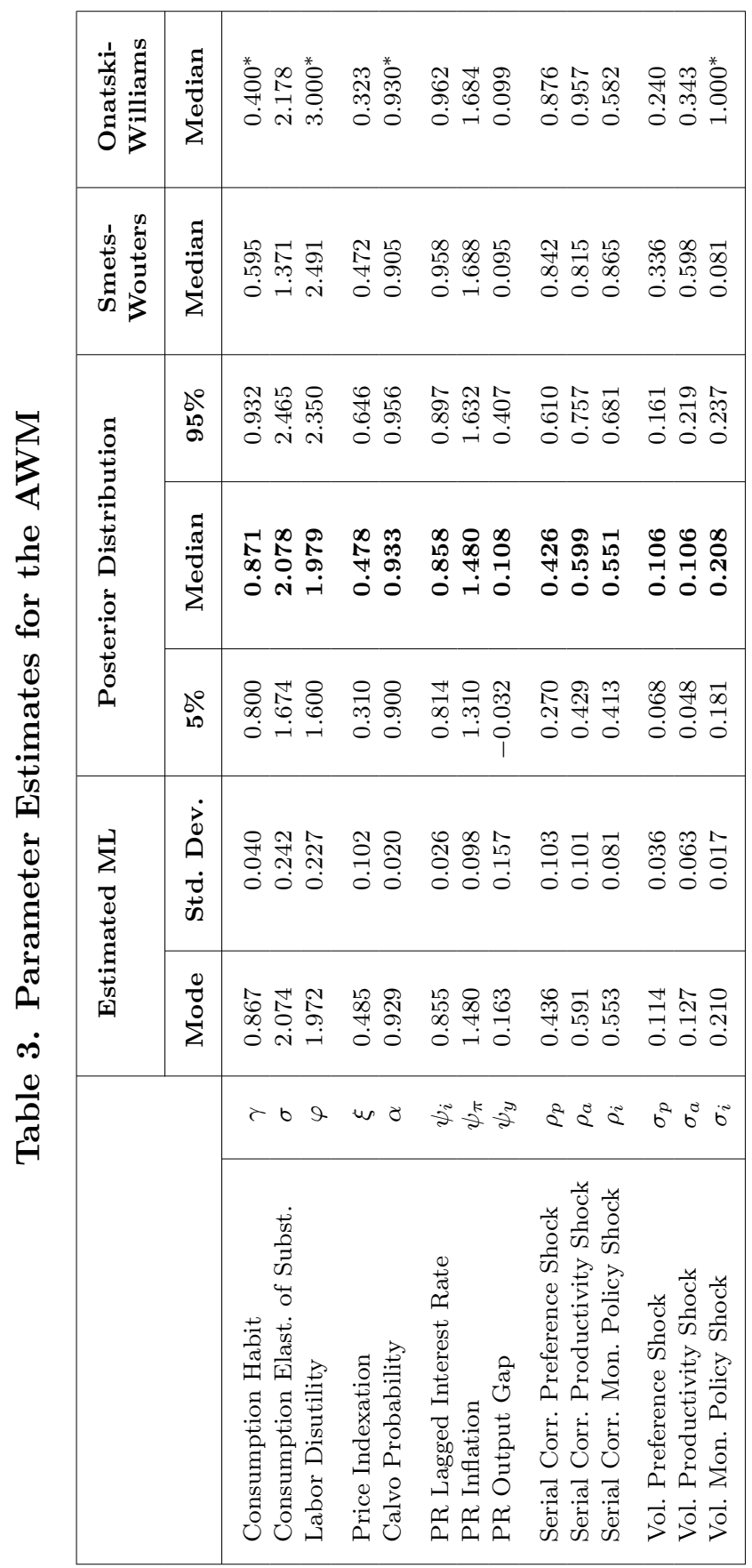


while the inverse of the elasticity of labor disutility $(\varphi)$ is equal to 1.98. These estimates are consistent with the MCM estimates. In contrast, the habit parameter $\gamma$ is as high as 0.87 . This estimate significantly differs from the MCM estimate and suggests that the aggregate model is more persistent than the multicountry model.

Focusing on the behavior of firms, the parameter of price indexation is $\xi=0.48$, while the probability that firms are not allowed to reoptimize their price is $\alpha=0.93$. The degree of price stickiness is rather large, since the average duration of price contracts is about fifteen quarters. This figure is somewhat larger than microeconomic evidence, but it is in the range of previous macroeconomic estimates (see Smets and Wouters 2003 and Onatski and Williams 2004).

The estimate of the monetary policy rule is only indicative of how short-term interest rates reacted to macroeconomic developments over the sample period. In the absence of a common central bank over the sample, this estimate cannot be taken as reflecting plausibly the behavior of monetary authorities. The long-run response to inflation is $\psi_{\pi}=1.5$, while the reaction to output gap is $\psi_{y}=0.11$. Once again, these estimates contrast sharply with the MCM estimates reported above.

The estimated model is able to capture most of the persistence found in the data. This translates to low estimates of the serial correlation of shocks. Our median estimates range between 0.43 and 0.6 .

To sum up, our estimates suggest that the AWM suffers from heterogeneity bias. This bias is sizable and significant for at least three key parameters that reflect the behavior of households (the habit persistence $\gamma$ ), firms (the Calvo probability $\alpha$ ), and monetary authorities (the reaction to output gap $\psi_{y}$ ). In all cases, it points toward a higher persistence in the dynamics of the AWM. Similar results have been reported in simpler models, such as those using autoregressive processes (Granger 1980). ${ }^{18}$

\footnotetext{
${ }^{18}$ Interestingly, Pytlarczyk (2005) finds very close estimates for common parameters (for Germany and the euro area) although using a more complicated model than those presented here.
} 


\section{Optimal Monetary Policy}

We now turn to the evaluation of the optimal monetary policy in the context of the euro area. Therefore, we acknowledge that there is a unique central bank within the euro area, and we keep the nominal exchange rate constant and equal to one within the area. An advantage of having developed a structural model based on optimizing behaviors is that it provides a natural objective for monetary policy - namely, the maximization of the welfare, defined as the expected utility of the representative household. Following Woodford (2003) and Giannoni and Woodford (2005), we compute the secondorder Taylor-series approximation to this objective function as a quadratic function of variables and shocks. Various aspects of our model, such as inflation inertia and external habit formation, require that we derive an appropriate welfare-based stabilization objective.

Two important issues arise when considering the evaluation of welfare in the context of an open economy with habit formation. First, as discussed in Rotemberg and Woodford (1998), under the assumption that the constant subsidy for output $\vartheta$ neutralizes the distortion associated with firms' market power, it can be shown that in a closed economy the optimal monetary policy is the one that replicates the flexible-price equilibrium allocation. ${ }^{19}$ In an open economy, as noted by Corsetti and Pesenti (2001) and Galí and Monacelli (2005), a second source of distortion comes from the fact that the transmission of monetary policy affects demand not only through the relative cost of borrowing but also through its effect on the terms of trade. This is a consequence of the imperfect substitutability between home and foreign goods, combined with sticky prices. As in Benigno and Benigno (2003), we assume that the subsidy for output exactly offsets the combined effects of market power and the terms-of-trade distortions in the steady state.

Second, in an open-economy framework, most previous studies investigated the way the optimal monetary policy may be designed for a given type of monetary arrangement between central banks.

\footnotetext{
${ }^{19}$ The intuition is straightforward: with the subsidy in place, there is only one distortion left in the economy - namely, sticky price. By stabilizing markups at their frictionless level, nominal rigidities cease to be binding, since firms do not feel any desire to adjust their price.
} 
Typical extreme cases are noncooperation and full cooperation. Our evaluation of the optimal monetary policy obviously presumes full cooperation, since only one central bank is involved. More specifically, our focus is not on whether coordination may improve the global welfare, but rather on whether the fully cooperative monetary policy should be based on an aggregated model or on a multicountry model.

\subsection{The Welfare Objective}

\subsubsection{Expression for the Welfare}

DSGE models deliver a natural measure of welfare based on the representative household's utility. It is defined as the conditional expectation of the current and discounted future values of the approximated utility function. In appendix 3, we derive the welfare for the two-country model. In the closed-economy version, which corresponds to our AWM, the aggregated welfare at date 0 can be approximated by

$$
\begin{aligned}
\mathcal{W}_{0}^{A W M} \approx & -\frac{\overline{\mathbb{U}}_{\bar{C}} \bar{C}_{2}}{2} \mathbb{E}_{0} \sum_{t=0}^{\infty} \beta^{t}\left\{\left(\hat{c}_{t}+\beta \gamma\right)^{2}+\left(\beta \gamma\left(1+\rho_{p}\right)-\sigma-1\right) \hat{c}_{t}^{2}\right. \\
& +\frac{\sigma}{1-\gamma}\left(\hat{c}_{t}-\gamma \hat{c}_{t-1}\right)^{2}+\left(\frac{\sigma}{1-\gamma}+\varphi\right)\left(\hat{c}_{t}-\hat{c}_{t}^{n}\right)^{2} \\
& -\frac{\sigma \gamma}{(1-\gamma)}\left(\hat{c}_{t}-\hat{c}_{t-1}^{n}\right)^{2}-\beta \gamma \rho_{p}\left(\hat{c}_{t}-\hat{\varepsilon}_{p, t}\right)^{2} \\
& \left.+\frac{\theta \alpha}{(1-\alpha)(1-\beta \alpha)}\left(\hat{\pi}_{t}-\xi \hat{\pi}_{t-1}\right)^{2}\right\}+t . i . p .
\end{aligned}
$$

where all variables denote area-wide variables and parameters are those pertaining to the AWM. $\hat{c}_{t}^{n}$ is the natural value of aggregate consumption and t.i.p. regroups terms independent of the actual policy. ${ }^{20}$ Expression (25) combines features implied by the introduction of inflation inertia and external habit formation. Interestingly, we notice that, in our estimated model, it is optimal for the central bank to put a much higher weight (about 100 times more) on the

\footnotetext{
${ }^{20}$ See appendix 2 for details on the $\log$-linearized flexible-price equilibrium.
} 
stabilization of goods price inflation than on the stabilization of the other variables. In addition, no concern about interest rate stabilization is present in this expression. This issue will be addressed in the subsequent sensitivity analysis.

The aggregated welfare in the two-country approach (taking into account the heterogeneity across countries) is defined as the weighted average of the national welfare functions:

$$
\mathcal{W}_{0}^{M C M}=n \mathcal{W}_{0}+(1-n) \mathcal{W}_{0}^{*},
$$

where $\mathcal{W}_{0}$ and $\mathcal{W}_{0}^{*}$ are detailed in appendix $3 .^{21}$

\subsubsection{Evaluation of the Optimal Policy Rule}

We evaluate the optimal monetary policy by taking the unconditional expectation of expressions (25) and (26) with respect to the distribution of exogenous shocks, and under the assumption that all endogenous variables in the initial period are at their unconditional expectation of zero. This assumption ensures that the desirability of the chosen plan does not depend upon initial conditions at time 0 . We thus define the unconditional expectation of the welfare as $\breve{\mathcal{W}}_{0}^{i}=(1-\beta) \mathbb{E} \mathcal{W}_{0}^{i}, i=M C M, A W M^{22}$

Since our aim is to compare the welfare consequences of adopting as forecasting model the (suboptimal) AWM instead of the MCM, we proceed as follows, considering two approaches in turn:

(i) In the multicountry approach, the central bank uses the MCM to forecast national variables. The policy rule is assumed to be defined in terms of aggregate variables, since the policy rule is designed on the basis of area-wide developments only. Its expression is given by

$$
\hat{\imath}_{t}=F_{M C M} \times \Xi \times \hat{s}_{t}^{M C M},
$$

\footnotetext{
${ }^{21}$ In the $N$-country case, the total welfare is given by $\mathcal{W}_{0}^{M C M}=\sum_{j=1}^{N} n_{j} \mathcal{W}_{0}^{j}$, where $n_{j}$ is the weight of the country $j$ in the euro-area GDP and $\sum_{j=1}^{N} n_{j}=1$. In our evaluation, we hold the following weights: 0.4 for Germany and 0.3 for France and Italy.

${ }^{22}$ By maximizing unconditional welfare, we are implicitly maximizing welfare in the steady state. This welfare comparison ignores the possibility of losses in welfare on the transition path from one steady state to another (see Schmitt-Grohé and Uribe 2004).
} 
where in a two-country setup

$$
\begin{aligned}
\hat{s}_{t}^{M C M}= & \left(\hat{\varepsilon}_{p, t}, \hat{\varepsilon}_{p, t}^{*}, \hat{a}_{t}, \hat{a}_{t}^{*}, \hat{c}_{t}^{n}, \hat{c}_{t}^{* n}, \hat{c}_{t-1}^{n}, \hat{c}_{t-1}^{* n}, \hat{c}_{t}, \hat{c}_{t}^{*}, \hat{c}_{t-1}, \hat{c}_{t-1}^{*},\right. \\
& \left.\hat{\pi}_{H, t}, \hat{\pi}_{F, t}^{*}, \hat{\imath}_{t-1}, \hat{\imath}_{t-1}^{*}\right)^{\prime}
\end{aligned}
$$

denotes the vector of state variables under the MCM, and $\Xi$ is an aggregation matrix that defines the area-wide aggregates as functions of country variables. Then, the constrained optimal monetary policy rule $\left(F_{M C M}\right)$ is obtained by maximizing the weighted average of national welfare functions (expression (26)), allowing cross-country heterogeneity of behaviors. It should be noted that this rule is not in general fully optimal under the MCM, since it imposes several constraints on the parameters of the rule. Indeed, domestic and foreign variables are constrained to have the same weight in the reaction function. ${ }^{23}$ The maximal value of welfare is denoted $\breve{\mathcal{W}}_{0}^{M C M}$. For further use, we also define the fully optimal policy rule as $F_{M C M}^{o p t}$ and the corresponding welfare as $\breve{\mathcal{W}}_{0}^{\text {opt }}$.

(ii) In the aggregated approach, the central bank forecasts areawide variables (using the AWM) and adopts a policy rule designed in terms of aggregate variables only, in the form

$$
\hat{\imath}_{t}=F_{A W M} \times \hat{s}_{t}^{A W M},
$$

where

$$
\hat{s}_{t}^{A W M}=\left(\hat{\varepsilon}_{p, t}, \hat{a}_{t}, \hat{c}_{t}^{n}, \hat{c}_{t-1}^{n}, \hat{c}_{t}, \hat{c}_{t-1}, \hat{\pi}_{t}, \hat{\imath}_{t-1}\right)^{\prime}
$$

denotes the vector of state variables under the AWM. The optimal monetary policy rule is then obtained by maximizing the aggregated welfare (expression (25)), assuming homogeneity of behaviors across countries. The resulting welfare would not be directly comparable to $\breve{\mathcal{W}}_{0}^{M C M}$, since the two expressions are evaluated under two different sets

\footnotetext{
${ }^{23}$ An important consequence is that it cannot be computed using the standard approach, based on solving the Bellman equation. Rather, the constrained rule $F_{M C M}$ is obtained by numerically maximizing the welfare among all policy rules that include aggregate variables only.
} 
of assumptions. To obtain comparable welfare functions, we evaluate the welfare associated with the AWM policy rule $\left(F_{A W M}\right)$ using the MCM. The welfare of the area is therefore computed as the weighted average of national welfares. This expression collapses to the aggregated welfare under full homogeneity only. The maximal value of welfare associated with the AWM policy rule but evaluated under the MCM is denoted $\breve{\mathcal{W}}_{0}^{A W M}$. We then deduce the cost of using the (suboptimal) aggregated approach from the comparison of $\breve{\mathcal{W}}_{0}^{A W M}$ and $\breve{\mathcal{W}}_{0}^{M C M}$.

\subsection{Welfare Implications of Heterogeneity}

The constrained optimal rule evaluated under the multicountry approach $\left(F_{M C M}\right)$ is expected to induce a higher welfare than the optimal rule under the aggregated approach $\left(F_{A W M}\right)$. The reason is that, although both rules are defined in terms of aggregate variables only, the parameters for $F_{M C M}$ are obtained by maximizing the welfare under the "true" model. Assessing whether the central bank should be concerned about heterogeneity therefore requires that the welfare cost of using the AWM be economically significant. For this purpose, we compute two measures that provide some information on the welfare reduction due to the use of the AWM.

The first measure gives the cost of using the suboptimal forecasting model AWM as a permanent percentage shift in steadystate aggregate consumption. It is defined by scaling the welfare $\operatorname{loss}\left(\breve{\mathcal{W}}_{0}^{A W M}-\breve{\mathcal{W}}_{0}^{M C M}\right)$ by $\overline{\mathbb{U}}_{\bar{C}} \bar{C}$ :

$$
\delta_{1}=-\frac{\breve{\mathcal{W}}_{0}^{A W M}-\breve{\mathcal{W}}_{0}^{M C M}}{\overline{\mathbb{U}}_{\bar{C}} \bar{C}} .
$$

This measure has been previously investigated by Erceg, Henderson, and Levin (2000), Amato and Laubach (2004), Tchakarov (2004), and Benigno and López-Salido (2006). ${ }^{24}$

${ }^{24}$ Since $\breve{\mathcal{W}}_{0}^{i}=(1-\beta) \mathbb{E}\left(\mathcal{W}_{0}^{i}\right)$, expression (27) is also equivalent to

$$
\delta_{1}=-(1-\beta) \frac{\mathbb{E}\left(\mathcal{W}_{0}^{A W M}\right)-\mathbb{E}\left(\mathcal{W}_{0}^{M C M}\right)}{\overline{\mathbb{U}}_{\bar{C}} \bar{C}},
$$

where the welfare functions are evaluated under the MCM. 
The second measure is the fraction of the gap (in terms of welfare) between the AWM-based rule and the fully optimal MCM-based rule that is filled by the constrained MCM-based rule. It is defined as

$$
\delta_{2}=\frac{\breve{\mathcal{W}}_{0}^{A W M}-\breve{\mathcal{W}}_{0}^{M C M}}{\breve{\mathcal{W}}_{0}^{A W M}-\breve{\mathcal{W}}_{0}^{\text {opt }}}
$$

This measure allows us to compare our evaluations with those performed by Angelini et al. (2002) and Monteforte and Siviero (2003) in the context of ad hoc loss functions.

Table 4 reports the welfare obtained for the various policy rules considered, using the median of the posterior distribution of estimated parameters. The table gives the welfare under the AWM, the constrained MCM, and the fully optimal MCM, as well as the two measures of welfare cost. We obtain that the use of the AWM to define the monetary policy rule implies a welfare reduction as compared with the use of the constrained MCM (shown in panel A, the benchmark estimate). If we measure the welfare cost as the permanent percentage shift in steady-state aggregate consumption, we obtain that a cost of using the AWM is equal to $\delta_{1}=0.0037$. This suggests that the steady-state aggregate consumption level obtained using the AWM is almost 0.37 percent lower than the steady-state aggregate consumption obtained using the constrained MCM. This evaluation of the cost of using a suboptimal forecasting model is rather large as compared with some previous welfare evaluations. ${ }^{25}$ Note, however, that the measure $\delta_{2}$ provides additional insight into the source of welfare loss in using an AWM. Indeed, it indicates that the constrained MCM-based rule makes up for 98 percent of the distance between the AWM-based rule and the fully optimal MCM-based rule. This result suggests that, consistent with previous evidence, this is not the use of a restricted policy rule based on aggregate variables that is costly, but rather the use of a suboptimal forecasting model.

\footnotetext{
${ }^{25}$ Benigno and López-Salido (2006) estimate the cost of monetary policies in the context of heterogeneous Phillips curves within the euro area. They obtain that the cost of using an HICP-targeting policy rule instead of the optimal monetary policy is about 0.02 percent of steady-state consumption.
} 


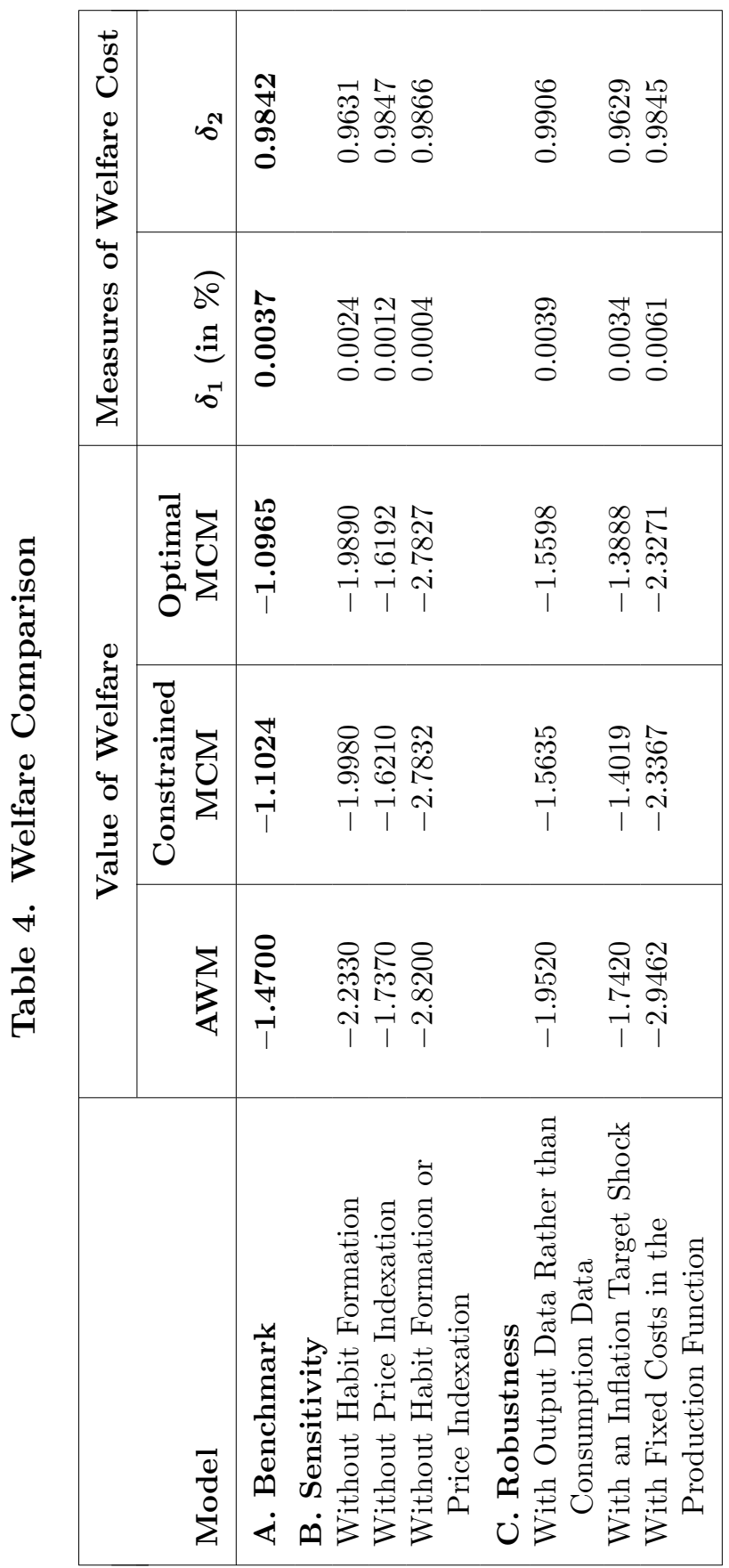




\subsection{Sensitivity Analysis}

As a first sensitivity exercise, we investigate the role of the two sources of endogenous persistence mechanisms we introduced in the model to reproduce the properties of the data-namely, external habit formation and price indexation. We measure how varying both of these assumptions affects the value of the cost of using an AWM rather than an MCM. To this end, we reestimate the AWM and the MCM under alternative assumptions, with and without habit formation and with and without price indexation (i.e., eight sets of estimates). In panel B of table 4, the second row reports the results for the two measures of welfare cost for the model without habit formation, the third row for the model without price indexation, and the fourth row without habit formation or price indexation. As may be expected, removing these friction mechanisms reduces the difference in welfare between the AWM and the MCM. Indeed, the welfare cost falls from 0.37 percent under the full specification to only 0.04 percent in the absence of habit formation and price indexation. We also notice that the welfare cost of using the AWM is more widely reduced when we assume no price indexation than when we assume no habit formation. In the former case, we obtain $\delta_{1}=0.12$ percent, while we have $\delta_{1}=0.24$ percent in the latter case. The main reason is that the price-indexation parameter $(\xi)$ affects the welfare through the expression $\left(\hat{\pi}_{t}-\xi \hat{\pi}_{t-1}\right)^{2}$, which has a weight on the aggregate welfare 100 times larger than the weights on the other variables. Therefore, the rather large welfare cost of using the AWM appears to be mainly attributable to the introduction in our model of price indexation rather than to habit formation. ${ }^{26}$

As a second sensitivity exercise, we investigate the role of interest rate smoothing, a feature that has been found to be necessary to reproduce the observed monetary policy rules. It is known that introducing a microfounded concern for interest rate smoothing is rather complicated, especially in the presence of habit formation (Woodford 2003). To eliminate this problem, we propose to simply include an ad hoc interest-rate-smoothing objective $\Lambda_{i}\left(\hat{\imath}_{t}-\hat{\imath}_{t-1}\right)^{2}$ in

\footnotetext{
${ }^{26}$ But we find that habit formation is very important for the model dynamics. Justiniano and Preston (2004) have also found such a result.
} 
the expressions (25) and (26) of the aggregate welfare. ${ }^{27}$ We focus on a grid over the weight on interest rate smoothing $\Lambda_{i}=[0,1]$. Figure 2 displays the value of the welfare cost for each weight. We first observe that introducing some concern for interest rate volatility in the welfare measure would not affect our main result that the use of the (suboptimal) AWM is costly as compared with a model that incorporates cross-country heterogeneity. Second, the larger the weight on interest rate smoothing, the higher the welfare cost. The welfare cost increases from $\delta_{1}=0.37$ percent when there is no interest rate smoothing to $\delta_{1}=0.86$ percent in the presence of strong interest rate smoothing $\left(\Lambda_{i}=1\right)$. This implies that, when we introduce an interest-rate-smoothing objective, the cost of using the AWM instead of the MCM is larger than under the baseline central bank preferences. The reason is that, under the AWM, the economy is less reactive to changes in the short-term interest rate. For instance, the consumption-habit and price-indexation parameters are larger in the AWM than in the MCM. Consequently, the central bank has to be more reactive and increase its short-term rate more severely, which in turn decreases the welfare.

\subsection{Robustness Analysis}

In this section, we address some robustness issues that may be raised by the specification we adopted to model European economies.

A first issue is related to the choice of consumption as opposed to output gap in the estimation of the model. Indeed, it may be argued that the specification adopted in the paper does not make explicit reference to the trade flows across countries. In fact, the MCM can be easily accommodated to include output as an observable variable in place of consumption, using equations (23) and (24). In this case, the trade flows across countries would be more transparent, although the genuine specification of the model would not be altered. Regarding the AWM, exactly the same specification can be estimated, since consumption and output are theoretically equivalent in our closed economy. Unreported evidence shows that the

\footnotetext{
${ }^{27}$ We have also replaced the interest-rate-smoothing objective $\left(\Lambda_{i}\left(\hat{\imath}_{t}-\hat{\imath}_{t-1}\right)^{2}\right)$ with the variance of the interest rate $\left(\Lambda_{i} \hat{\imath}_{t}^{2}\right)$, without finding any significant difference.
} 
Figure 2. Welfare Losses with Interest Rate Smoothing

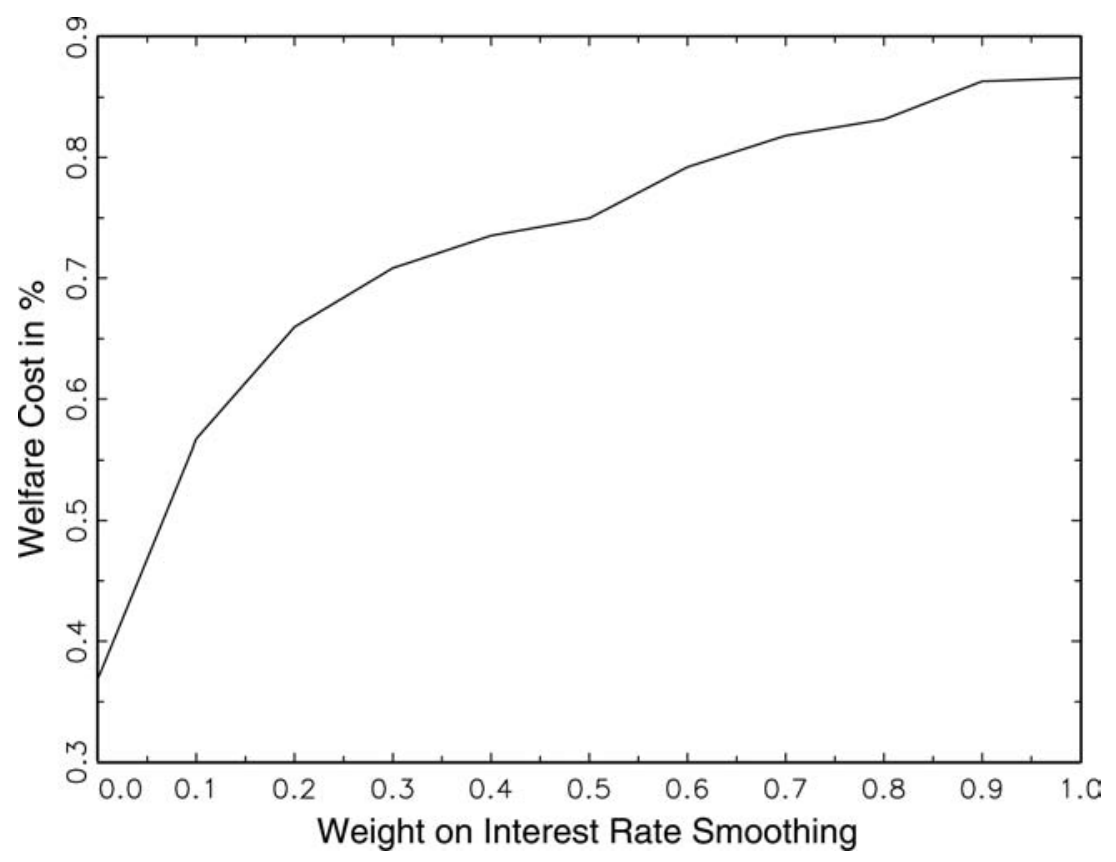

choice of output in place of consumption mainly results in a decrease of the overall persistence of the system. ${ }^{28}$ The habit parameter $\gamma$ decreases in all countries, consistent with the more volatile dynamics of output. The Calvo parameter and the interest-rate-smoothing parameter are also affected in the same direction, but to a lesser extent. As table 4 reveals (first row of panel C), the consequences on welfare costs are negligible.

A second issue relies on detrending. As described above, nominal interest and inflation rates in Europe have a downward trend over the estimation period. We took this trend into account by linearly detrending these series. Clearly, this might bias our estimates and the subsequent welfare analysis. A first solution would be to estimate the model in levels instead of deviations from trends. However, it would raise additional difficulties - in particular, due to the

\footnotetext{
${ }^{28}$ All the results presented in this section are in the technical appendix available upon request from the authors.
} 
near nonstationarity of the original series. An alternative approach consists of introducing a time-varying inflation target. ${ }^{29}$ We assume that this shock follows a first-order autoregressive process, as in Smets and Wouters (2003). Estimation of this model results in an increase in the parameters driving the persistence of the system. This was expected, given that inflation and interest rates are no longer detrended. However, when we turn to the welfare evaluation, we observe that the cost of using the suboptimal AWM is not significantly altered $\left(\delta_{1}=0.34\right.$ percent $)$.

As a last robustness check, we consider a model with fixed costs in the production function, as in Rotemberg and Woodford (1998). The main objective of this specification is to ensure that economic profits are equal to zero at the steady state. In the presence of fixed costs, the welfare has to be redefined accordingly, so that the welfare cost of using the AWM is very likely to be affected. Our estimates indicate that fixed costs play a significant role in the model, since the share of the fixed costs in production is significant in all countries (50 percent for the AWM; between 10 percent and 30 percent in the MCM). We still have a perfect illustration of the aggregation bias. In addition, this specification seems to generate more internal persistence since Calvo parameters and habit parameters, for instance, increase (implying a decrease in the serial correlation of shocks). In terms of welfare, we observe in the last row of table 4 (panel C) a significant increase in the welfare cost of using the AWM as a forecasting model. It is now almost twice the benchmark estimate $\left(\delta_{1}=0.61\right.$ percent instead of 0.37 percent). The reason may come from two sources: (i) a modification of the welfare expression (introducing a fixed cost is not neutral) and (ii) a change in the structural parameters.

\section{Conclusion}

In this paper, we evaluate the cost of ignoring the cross-country heterogeneity within the euro area when implementing the optimal monetary policy. To address this issue, we develop a multicountry DSGE model, which is used to estimate the dynamics of national

\footnotetext{
${ }^{29}$ Such a shock appears simultaneously in the Phillips curve and in the monetary policy rule.
} 
economies within the euro area. This model incorporates frictions required to reproduce the persistence of the actual data, including the presence of sticky-price setting and external habit formation in consumption. An additional characteristic of the model is the introduction of heterogeneous behaviors across countries that allows us to investigate the cost of using an AWM instead of an MCM.

Using Bayesian techniques, we estimate the MCM and AWM and provide evidence that the behavioral parameters in Germany, France, and Italy display some significant differences, and that shocks affecting the different economies are only very weakly correlated. Our results therefore highlight that heterogeneity can be mainly attributable to the asymmetry of shocks across countries rather than to differences in the behavioral parameters.

Since our model is suitable for the analysis of optimal monetary policy, we then compare the two models on the basis of their ability to maximize the welfare of the area-wide representative household. The welfare costs associated with the two optimal rules are then compared, allowing heterogeneity of behaviors. We find that using an AWM generates a relatively large welfare loss that corresponds to a permanent decrease in steady-state aggregate consumption by around 0.37 percent. Our results also suggest that this is not the use of a rule based on aggregate variables that is costly in terms of welfare, but rather the use of a suboptimal forecasting model. Moreover, the rather large welfare cost of using the AWM appears to be mainly attributable to the introduction in our model of price indexation rather than to habit formation. Finally, we investigate the implications of heterogeneity when an additional ad hoc interestrate-smoothing objective is allowed. Introducing some concern for interest rate volatility in the welfare measure would not affect the previous results.

It may be argued that the cost of designing, estimating, and using an MCM is rather large, suggesting that the AWM would be less costly to implement. However, our estimate of the difference between the AWM and the MCM in terms of welfare is very sizable. In addition, it is worth emphasizing that our evaluation is based on the three largest countries of the area that may be viewed as very similar economies. It is likely that including additional economies 
would even widen the discrepancies between the two models. Using larger models incorporating different fiscal policies and labor market characteristic (i.e., increasing heterogeneity) should also tend toward higher welfare losses.

\section{Appendix 1. The Log-Linearized Dynamic Equilibrium}

This appendix displays the log-linearized dynamic equilibrium in the case of a two-country model. $\hat{x}_{t}$ denotes the log-deviation from the steady-state value $\bar{x}$, i.e., $\hat{x}_{t}=\log \left(x_{t} / \bar{x}\right)$.

\section{Model}

- Home IS curve:

$$
\begin{aligned}
\hat{c}_{t}= & \frac{\gamma}{1+\gamma} \hat{c}_{t-1}+\frac{1}{1+\gamma} \mathbb{E}_{t} \hat{c}_{t+1}-\frac{(1-\gamma)}{(1+\gamma) \sigma}\left(\hat{\imath}_{t}-\mathbb{E}_{t} \hat{\pi}_{H, t+1}\right) \\
& +\frac{(1-\gamma)(1-\omega)}{(1+\gamma) \sigma} \mathbb{E}_{t} \Delta \hat{\tau}_{t+1}+\frac{\left(1-\rho_{p}\right)(1-\gamma)}{(1+\gamma) \sigma} \hat{\varepsilon}_{p, t}
\end{aligned}
$$

- Home Phillips curve:

$$
\hat{\pi}_{H, t}=\frac{\xi}{1+\beta \xi} \hat{\pi}_{H, t-1}+\frac{\beta}{1+\beta \xi} \mathbb{E}_{t} \hat{\pi}_{H, t+1}+\frac{(1-\beta \alpha)(1-\alpha)}{(1+\beta \xi) \alpha} \widehat{m c}_{t}
$$

- Home marginal cost:

$$
\begin{aligned}
\widehat{m c}_{t}= & \left(\frac{\sigma}{1-\gamma}+\varphi \omega s\right) \hat{c}_{t}-\frac{\gamma \sigma}{1-\gamma} \hat{c}_{t-1}+\varphi(1-\omega s) \hat{c}_{t}^{*}-(1+\varphi) \hat{\varepsilon}_{a, t} \\
& +\left[(1-\omega)(1+\varphi \omega s)+\varphi\left(1-\omega^{*}\right)(1-\omega s)\right] \hat{\tau}_{t}
\end{aligned}
$$

- Home aggregate output:

$$
\hat{y}_{t}=\left[(1-\omega) \omega s+\left(1-\omega^{*}\right)(1-\omega s)\right] \hat{\tau}_{t}+\omega s \hat{c}_{t}+(1-\omega s) \hat{c}_{t}^{*}
$$

- Home preference shock:

$$
\hat{\varepsilon}_{p, t}=\rho_{p} \hat{\varepsilon}_{p, t-1}+\eta_{p, t}
$$

- Home productivity shock:

$$
\hat{\varepsilon}_{a, t}=\rho_{a} \hat{\varepsilon}_{a, t-1}+\eta_{a, t}
$$


- Foreign IS curve:

$$
\begin{aligned}
\hat{c}_{t}^{*}= & \frac{\gamma^{*}}{1+\gamma^{*}} \hat{c}_{t-1}^{*}+\frac{1}{1+\gamma^{*}} \mathbb{E}_{t} \hat{c}_{t+1}^{*}-\frac{\left(1-\gamma^{*}\right)}{\left(1+\gamma^{*}\right) \sigma^{*}}\left(\hat{\imath}_{t}^{*}-\mathbb{E}_{t} \hat{\pi}_{F, t+1}^{*}\right) \\
& -\frac{\left(1-\gamma^{*}\right) \omega^{*}}{\left(1+\gamma^{*}\right) \sigma^{*}} \mathbb{E}_{t} \Delta \hat{\tau}_{t+1}+\frac{\left(1-\rho_{p}^{*}\right)\left(1-\gamma^{*}\right)}{\left(1+\gamma^{*}\right) \sigma^{*}} \hat{\varepsilon}_{p, t}^{*}
\end{aligned}
$$

- Foreign Phillips curve:

$$
\begin{aligned}
\hat{\pi}_{F, t}^{*}= & \frac{\xi^{*}}{1+\beta \xi^{*}} \hat{\pi}_{F, t-1}^{*}+\frac{\beta}{1+\beta \xi^{*}} \mathbb{E}_{t} \hat{\pi}_{F, t+1}^{*} \\
& +\frac{\left(1-\beta \alpha^{*}\right)\left(1-\alpha^{*}\right)}{\left(1+\beta \xi^{*}\right) \alpha^{*}} \widehat{m c}_{t}^{*}
\end{aligned}
$$

- Foreign marginal cost:

$$
\begin{aligned}
\widehat{m c}_{t}^{*}= & \left(\frac{\sigma^{*}}{1-\gamma^{*}}+\varphi^{*}\left(1-\omega^{*}\right) s^{*}\right) \hat{c}_{t}^{*}-\frac{\gamma^{*} \sigma^{*}}{1-\gamma^{*}} \hat{c}_{t-1}^{*} \\
& +\varphi^{*}\left[1-\left(1-\omega^{*}\right) s^{*}\right] \hat{c}_{t}-\left(1+\varphi^{*}\right) \hat{\varepsilon}_{a, t}^{*} \\
& -\left[\omega\left[1+\varphi^{*}\left(1-\left(1-\omega^{*}\right) s^{*}\right)\right]+\omega^{*} \varphi^{*}\left(1-\omega^{*}\right) s^{*}\right] \hat{\tau}_{t}
\end{aligned}
$$

- Foreign aggregate output:

$$
\begin{aligned}
\hat{y}_{t}^{*}= & {\left[1-\left(1-\omega^{*}\right) s^{*}\right] \hat{c}_{t}+\left(1-\omega^{*}\right) s^{*} \hat{c}_{t}^{*}-\left(\omega\left[1-\left(1-\omega^{*}\right) s^{*}\right]\right.} \\
& \left.+\omega^{*}\left(1-\omega^{*}\right) s^{*}\right) \hat{\tau}_{t}
\end{aligned}
$$

- Foreign preference shock:

$$
\hat{\varepsilon}_{p, t}^{*}=\rho_{p}^{*} \hat{\varepsilon}_{p, t-1}^{*}+\eta_{p, t}^{*}
$$

- Foreign productivity shock:

$$
\hat{\varepsilon}_{a, t}^{*}=\rho_{a}^{*} \hat{\varepsilon}_{a, t-1}^{*}+\eta_{a, t}^{*}
$$

- Terms of trade:

$$
\begin{aligned}
\hat{\tau}_{t}= & \frac{1}{\omega-\omega^{*}}\left[\frac{\sigma}{1-\gamma} \hat{c}_{t}-\frac{\gamma \sigma}{1-\gamma} \hat{c}_{t-1}-\frac{\sigma^{*}}{1-\gamma^{*}} \hat{c}_{t}^{*}\right. \\
& \left.+\frac{\gamma^{*} \sigma^{*}}{1-\gamma^{*}} \hat{c}_{t-1}^{*}+\hat{\varepsilon}_{p, t}^{*}-\hat{\varepsilon}_{p, t}\right]
\end{aligned}
$$


Notice that $s=\bar{C} / \bar{Y}$ and $s^{*}=\bar{C}^{*} / \bar{Y}^{*}$.

Taylor-Type Rules

- Home monetary policy rule:

$$
\hat{\imath}_{t}=\psi_{i} \hat{\imath}_{t-1}+\left(1-\psi_{i}\right)\left[\psi_{\pi} \hat{\pi}_{H, t}+\psi_{y}\left(\hat{y}_{t}-\hat{y}_{t}^{n}\right)\right]+\hat{\varepsilon}_{i, t}
$$

- Foreign monetary policy rule:

$$
\hat{\imath}_{t}^{*}=\psi_{i}^{*} \hat{\imath}_{t-1}^{*}+\left(1-\psi_{i}^{*}\right)\left[\psi_{\pi}^{*} \hat{\pi}_{F, t}^{*}+\psi_{y}^{*}\left(\hat{y}_{t}^{*}-\hat{y}_{t}^{* n}\right)\right]+\hat{\varepsilon}_{i, t}^{*}
$$

- Home monetary policy shock:

$$
\hat{\varepsilon}_{i, t}=\rho_{i} \hat{\varepsilon}_{i, t-1}+\eta_{i, t}
$$

- Foreign monetary policy shock:

$$
\hat{\varepsilon}_{i, t}^{*}=\rho_{i}^{*} \hat{\varepsilon}_{i, t-1}^{*}+\eta_{i, t}^{*}
$$

\section{Appendix 2. The Log-Linearized Flexible-Price Output}

The so-called natural output is obtained as the level of output that would prevail under flexible prices in the absence of cost-push shocks. In this case, the optimal pricing decision for the firm $h$-i.e., the price that would maximize profits at each period - is given by

$$
P_{H, t}(h)=\frac{\mu}{(1+\vartheta)} \frac{W_{t}}{\varepsilon_{a, t}},
$$

where $\mu \equiv \theta /(\theta-1)$ is the optimal markup and $\vartheta$ is the subsidy for output that offsets the effect on imperfect competition in goods markets on the steady-state level of output. Using the demand for $\operatorname{good} h, Y_{t}(h)=\left(\frac{P_{H, t}(h)}{P_{H, t}}\right)^{-\theta} Y_{t}$, we note that the relative supply of good $h$ must in turn satisfy

$$
\left(\frac{Y_{t}(h)}{Y_{t}}\right)^{-1 / \theta}=\frac{\mu}{(1+\vartheta)} \frac{W_{t}}{P_{H, t} \varepsilon_{a, t}} .
$$

Note also that, in steady state,

$$
\frac{\overline{\mathcal{U}}_{\bar{L}}}{\overline{\mathcal{U}}_{\bar{C}}}=\frac{(1+\vartheta)}{\mu}=1 \text {. }
$$


Because all wages are the same in the case of flexible wages, we have $W_{t}(h)=W_{t}$ and $L_{t}(h)=L_{t}$ for all $h$. This implies that all sellers supply a quantity $Y_{t}^{n}$ satisfying

$$
\begin{aligned}
1 & =\frac{\mathcal{U}_{L^{n}, t}}{\mathcal{U}_{C^{n}, t}} \frac{P_{t}}{P_{H, t}} \frac{1}{\varepsilon_{a, t}}=\frac{\left(L_{t}^{n}\right)^{\varphi}}{\left(C_{t}^{n}-\gamma C_{t}^{n}\right)^{-\sigma}} \frac{\left(\mathcal{T}_{t}^{n}\right)^{1-\omega}}{\varepsilon_{a, t}} \\
& =\frac{\left(Y_{t}^{n} / \varepsilon_{a, t}\right)^{\varphi}}{\left(C_{t}^{n}-\gamma C_{t-1}^{n}\right)^{-\sigma}} \frac{\left(\mathcal{T}_{t}^{n}\right)^{1-\omega}}{\varepsilon_{a, t}} .
\end{aligned}
$$

Log-linearizing this expression yields

$$
\hat{y}_{t}^{n}=-\frac{\sigma}{(1-\gamma) \varphi} \hat{c}_{t}^{n}+\frac{\sigma \gamma}{(1-\gamma) \varphi} \hat{c}_{t-1}^{n}-\frac{(1-\omega)}{\varphi} \hat{\tau}_{t}^{n}+\frac{(1+\varphi)}{\varphi} \hat{\varepsilon}_{a, t} .
$$

By using the terms-of-trade expression

$$
\begin{aligned}
\hat{\tau}_{t}^{n}= & \frac{1}{\omega-\omega^{*}}\left[\frac{\sigma}{1-\gamma} \hat{c}_{t}^{n}-\frac{\gamma \sigma}{1-\gamma} \hat{c}_{t-1}^{n}-\frac{\sigma^{*}}{1-\gamma^{*}} \hat{c}_{t}^{* n}\right. \\
& \left.+\frac{\gamma^{*} \sigma^{*}}{1-\gamma^{*}} \hat{c}_{t-1}^{* n}+\hat{\varepsilon}_{p, t}^{*}-\hat{\varepsilon}_{p, t}\right]
\end{aligned}
$$

with the definition of the aggregate output

$$
\hat{y}_{t}^{n}=\omega s \hat{c}_{t}^{n}+(1-\omega s) \hat{c}_{t}^{n *}+\left[(1-\omega) \omega s+\left(1-\omega^{*}\right)(1-\omega s)\right] \hat{\tau}_{t}^{n},
$$

we obtain

$$
\begin{aligned}
& \left(\frac{\sigma}{1-\gamma}+\varphi \omega s+\frac{\sigma \Psi}{(1-\gamma)}\right) \hat{c}_{t}^{n}=\frac{\gamma \sigma}{1-\gamma}(1+\Psi) \hat{c}_{t-1}^{n} \\
& \quad-\left(\varphi(1-\omega s)-\frac{\sigma^{*} \Psi}{\left(1-\gamma^{*}\right)}\right) \hat{c}_{t}^{* n}-\frac{\gamma^{*} \sigma^{*} \Psi}{\left(1-\gamma^{*}\right)} \hat{c}_{t-1}^{* n} \\
& \quad-\Psi\left(\hat{\varepsilon}_{p, t}^{*}-\hat{\varepsilon}_{p, t}\right)+(1+\varphi) \hat{\varepsilon}_{a, t}
\end{aligned}
$$

and

$$
\begin{aligned}
\hat{y}_{t}^{n}= & \left(\omega s+\frac{\sigma \tilde{\Psi}}{(1-\gamma)}\right) \hat{c}_{t}^{n}-\left(\frac{\gamma \sigma \tilde{\Psi}}{(1-\gamma)}\right) \hat{c}_{t-1}^{n}+\left(1-\omega s-\frac{\sigma^{*} \tilde{\Psi}}{\left(1-\gamma^{*}\right)}\right) \hat{c}_{t}^{* n} \\
& +\left(\frac{\gamma^{*} \sigma^{*} \tilde{\Psi}}{\left(1-\gamma^{*}\right)}\right) \hat{c}_{t-1}^{* n}+\tilde{\Psi}\left(\hat{\varepsilon}_{p, t}^{*}-\hat{\varepsilon}_{p, t}\right)
\end{aligned}
$$


where $\Psi=\left[(1-\omega)(1+\varphi \omega s)+\varphi\left(1-\omega^{*}\right)(1-\omega s)\right] /\left(\omega-\omega^{*}\right)$ and $\tilde{\Psi}=\left[(1-\omega) \omega s+\left(1-\omega^{*}\right)(1-\omega s)\right] /\left(\omega-\omega^{*}\right)$.

The same calculations for the foreign country yield

$$
\begin{aligned}
& \left(\frac{\sigma^{*}}{1-\gamma^{*}}+\varphi^{*}\left(1-\omega^{*}\right) s^{*}+\frac{\sigma^{*} \Psi^{*}}{\left(1-\gamma^{*}\right)}\right) \hat{c}_{t}^{* n}=\frac{\gamma^{*} \sigma^{*}}{1-\gamma^{*}}\left(1+\Psi^{*}\right) \hat{c}_{t-1}^{* n} \\
& \quad-\left(\varphi^{*}\left[1-\left(1-\omega^{*}\right) s^{*}\right]-\frac{\sigma \Psi^{*}}{(1-\gamma)}\right) \hat{c}_{t}^{n}-\frac{\gamma \sigma \Psi^{*}}{(1-\gamma)} \hat{c}_{t-1}^{n} \\
& \quad+\Psi^{*}\left(\hat{\varepsilon}_{p, t}^{*}-\hat{\varepsilon}_{p, t}\right)+\left(1+\varphi^{*}\right) \hat{\varepsilon}_{a, t}^{*}
\end{aligned}
$$

and

$$
\begin{aligned}
\hat{y}_{t}^{* n}= & {\left[1-\left(1-\omega^{*}\right) s^{*}-\frac{\sigma \tilde{\Psi}^{*}}{(1-\gamma)}\right] \hat{c}_{t}^{n}+\frac{\gamma \sigma \tilde{\Psi}^{*}}{(1-\gamma)} \hat{c}_{t-1}^{n} } \\
& +\left(\left(1-\omega^{*}\right) s^{*}+\frac{\sigma^{*} \tilde{\Psi}^{*}}{\left(1-\gamma^{*}\right)}\right) \hat{c}_{t}^{* n}-\frac{\gamma^{*} \sigma^{*} \tilde{\Psi}^{*}}{\left(1-\gamma^{*}\right)} \hat{c}_{t-1}^{* n} \\
& -\tilde{\Psi}^{*}\left(\hat{\varepsilon}_{p, t}^{*}-\hat{\varepsilon}_{p, t}\right)
\end{aligned}
$$

where $\Psi^{*}=\left[\omega\left[1+\varphi^{*}\left(1-\left(1-\omega^{*}\right) s^{*}\right)\right]+\omega^{*} \varphi^{*}\left(1-\omega^{*}\right) s^{*}\right] /\left(\omega-\omega^{*}\right)$ and $\tilde{\Psi}^{*}=\left(\omega\left[1-\left(1-\omega^{*}\right) s^{*}\right]+\omega^{*}\left(1-\omega^{*}\right) s^{*}\right) /\left(\omega-\omega^{*}\right)$.

\section{Appendix 3. Approximation of the Welfare Criterion}

The second-order approximation of the home representative household's utility is derived in this section, using methods discussed in more detail in Woodford (2003). The average utility flow of the representative household at date $t$ is given by

$$
\mathbb{W}_{t}=\mathbb{U}\left(C_{t}, \mathcal{H}_{t}, \varepsilon_{p, t}\right)-\frac{1}{n} \int_{0}^{n} \mathbb{V}\left(L_{t}(h), \varepsilon_{p, t}\right) \mathrm{d} h
$$

where

$$
\begin{aligned}
\mathbb{U}\left(C_{t}, \mathcal{H}_{t}, \varepsilon_{p, t}\right)= & \frac{\varepsilon_{p, t}}{1-\sigma}\left(C_{t}-\gamma \mathcal{H}_{t}\right)^{1-\sigma} \text { and } \\
& \mathbb{V}\left(L_{t}(h), \varepsilon_{p, t}\right)=\frac{\varepsilon_{p, t}}{1+\varphi}\left(L_{t}(h)\right)^{1+\varphi}
\end{aligned}
$$




\section{Taylor Expansion of the Utility Function}

The second-order Taylor expansion of $\mathbb{U}\left(C_{t}, \mathcal{H}_{t}, \varepsilon_{p, t}\right)$ around the steady state $\overline{\mathbb{U}}=\mathbb{U}\left(\bar{C}, \overline{\mathcal{H}}, \bar{\varepsilon}_{p}\right)$ yields

$$
\begin{aligned}
\mathbb{U}\left(C_{t}, \mathcal{H}_{t}, \varepsilon_{p, t}\right) \approx & \overline{\mathbb{U}}+\overline{\mathbb{U}}_{\bar{C}} \tilde{C}_{t}+\overline{\mathbb{U}}_{\overline{\mathcal{H}}} \tilde{\mathcal{H}}_{t}+\overline{\mathbb{U}}_{\bar{\varepsilon}_{p}} \tilde{\varepsilon}_{p, t}+\frac{1}{2} \overline{\mathbb{U}}_{\bar{C} \bar{C}} \tilde{C}_{t}^{2} \\
& +\frac{1}{2} \overline{\mathbb{U}}_{\overline{\mathcal{H}} \overline{\mathcal{H}}} \tilde{\mathcal{H}}_{t}^{2}+\frac{1}{2} \overline{\mathbb{U}}_{\bar{\varepsilon}_{p} \bar{\varepsilon}_{p}}\left(\tilde{\varepsilon}_{p, t}\right)^{2}+\overline{\mathbb{U}}_{\bar{C} \overline{\mathcal{H}}} \tilde{C}_{t} \tilde{\mathcal{H}}_{t} \\
& +\overline{\mathbb{U}}_{\bar{C} \bar{\varepsilon}_{p}} \tilde{C}_{t} \tilde{\varepsilon}_{p, t}+\overline{\mathbb{U}}_{\overline{\mathcal{H}} \bar{\varepsilon}_{p}} \tilde{\mathcal{H}}_{t} \tilde{\varepsilon}_{p, t}+\mathcal{O}\left(\|\zeta\|^{3}\right),
\end{aligned}
$$

where $\tilde{X}_{t}=X_{t}-\bar{X}, \mathcal{O}\left(\|\zeta\|^{3}\right)$ denotes the order of residual and $\|\zeta\|$ is a bound on the amplitude of exogenous disturbances.

Applying a second-order Taylor expansion $\left(\tilde{X}_{t} / \bar{X}=\hat{x}_{t}+\frac{1}{2} \hat{x}_{t}^{2}+\right.$ $\mathcal{O}\left(\|\zeta\|^{3}\right)$, where $\left.\hat{x}_{t}=\ln X_{t}-\ln \bar{X}\right)$, we obtain

$$
\begin{aligned}
\mathbb{U}\left(C_{t}, \mathcal{H}_{t}, \varepsilon_{p, t}\right) \approx & \overline{\mathbb{U}}+\overline{\mathbb{U}}_{\bar{C}} \bar{C}\left(\hat{c}_{t}+\frac{1}{2} \hat{c}_{t}^{2}\right)+\overline{\mathbb{U}}_{\overline{\mathcal{H}}} \overline{\mathcal{H}}\left(\hat{h}_{t}+\frac{1}{2} \hat{h}_{t}^{2}\right) \\
& +\overline{\mathbb{U}}_{\bar{\varepsilon}_{p}} \bar{\varepsilon}_{p}\left(\hat{\varepsilon}_{p, t}+\frac{1}{2} \hat{\varepsilon}_{p, t}^{2}\right)+\frac{1}{2} \overline{\mathbb{U}}_{\bar{C} \bar{C}} \bar{C}^{2} \hat{c}_{t}^{2} \\
& +\frac{1}{2} \overline{\mathbb{U}}_{\overline{\mathcal{H}} \overline{\mathcal{H}}} \overline{\mathcal{H}}^{2} \hat{h}_{t}^{2}+\frac{1}{2} \overline{\mathbb{U}}_{\bar{\varepsilon}_{p} \bar{\varepsilon}_{p}} \bar{\varepsilon}_{p}^{2} \hat{\varepsilon}_{p, t}^{2}+\overline{\mathbb{U}}_{\bar{C} \overline{\mathcal{H}}} \bar{C} \overline{\mathcal{H}}\left(\hat{c}_{t} \hat{h}_{t}\right) \\
& +\overline{\mathbb{U}}_{\bar{C} \bar{\varepsilon}_{p}} \bar{C} \bar{\varepsilon}_{p}\left(\hat{c}_{t} \hat{\varepsilon}_{p, t}\right)+\overline{\mathbb{U}}_{\overline{\mathcal{H}}_{\bar{\varepsilon}_{p}}} \overline{\mathcal{H}} \bar{\varepsilon}_{p}\left(\hat{h}_{t} \hat{\varepsilon}_{p, t}\right)+\mathcal{O}\left(\|\zeta\|^{3}\right)
\end{aligned}
$$

with

$$
\begin{aligned}
& \overline{\mathbb{U}}_{\bar{C}}=\bar{\varepsilon}_{p}(\bar{C}-\gamma \overline{\mathcal{H}})^{-\sigma}, \\
& \overline{\mathbb{U}}_{\bar{C} \bar{C}}=-\sigma \bar{\varepsilon}_{p}(\bar{C}-\gamma \overline{\mathcal{H}})^{-\sigma-1}=\frac{-\sigma}{(\bar{C}-\gamma \overline{\mathcal{H}})} \overline{\mathbb{U}}_{\bar{C}}, \\
& \overline{\mathbb{U}}_{\overline{\mathcal{H}}}=-\gamma \bar{\varepsilon}_{p}(\bar{C}-\gamma \overline{\mathcal{H}})^{-\sigma}=-\gamma \overline{\mathbb{U}}_{\bar{C}}, \\
& \overline{\mathbb{U}}_{\overline{\mathcal{H}} \overline{\mathcal{H}}}=-\gamma^{2} \sigma \bar{\varepsilon}_{p}(\bar{C}-\gamma \overline{\mathcal{H}})^{-\sigma-1}=\frac{-\gamma{ }^{2} \sigma}{(\bar{C}-\gamma \overline{\mathcal{H}})} \overline{\mathbb{U}}_{\bar{C}}, \\
& \overline{\mathbb{U}}_{\bar{C} \overline{\mathcal{H}}}=\sigma \gamma \bar{\varepsilon}_{p}(\bar{C}-\gamma \overline{\mathcal{H}})^{-\sigma-1}=\frac{\sigma \gamma}{(\bar{C}-\gamma \overline{\mathcal{H}})} \overline{\mathbb{U}}_{\bar{C}}, \\
& \overline{\mathbb{U}}_{\bar{\varepsilon}_{p}}=\frac{1}{1-\sigma}(\bar{C}-\gamma \overline{\mathcal{H}})^{1-\sigma}=\frac{(\bar{C}-\gamma \overline{\mathcal{H}})}{(1-\sigma) \overline{\mathbb{U}}_{\bar{C}}}, \\
& \overline{\mathbb{U}}_{\bar{\varepsilon}_{p} \bar{\varepsilon}_{p}}=0 \\
& \overline{\mathbb{U}}_{\bar{C} \bar{\varepsilon}_{p}}=(\bar{C}-\gamma \overline{\mathcal{H}})^{-\sigma}=\frac{\overline{\mathbb{U}}_{\bar{C}}}{\bar{\varepsilon}_{p}}, \\
& \overline{\mathbb{U}}_{\overline{\mathcal{H}} \bar{\varepsilon}_{p}}=-\gamma(\bar{C}-\gamma \mathcal{\mathcal { H }})^{-\sigma}=\frac{-\gamma}{\bar{\varepsilon}_{p}} \overline{\mathbb{U}}_{\bar{C}} .
\end{aligned}
$$


Replacing $\mathcal{H}_{t}$ with $C_{t-1}$, the utility of consumption simplifies to

$$
\begin{aligned}
\mathbb{U}\left(C_{t}, C_{t-1}, \varepsilon_{p, t}\right) \approx & \overline{\mathbb{U}}_{\bar{C}} \bar{C}\left\{\left(\hat{c}_{t}-\gamma \hat{c}_{t-1}\right)+\frac{1}{2}\left(\hat{c}_{t}^{2}-\gamma \hat{c}_{t-1}^{2}\right)\right. \\
& \left.-\frac{\sigma}{2(1-\gamma)}\left(\hat{c}_{t}-\gamma \hat{c}_{t-1}\right)^{2}+\hat{c}_{t} \hat{\varepsilon}_{p, t}-\gamma \hat{c}_{t-1} \hat{\varepsilon}_{p, t}\right\} \\
& + \text { t.i.p. }+\mathcal{O}\left(\|\zeta\|^{3}\right),
\end{aligned}
$$

where t.i.p. denotes terms independent of the actual policy, such as constant terms involving only exogenous variables.

Taylor Expansion of the Disutility of Work

The second-order Taylor expansion for $\mathbb{V}\left(L_{t}(h), \varepsilon_{p, t}\right)$ around the steady state $\overline{\mathbb{V}}=\mathbb{V}\left(\bar{L}, \bar{\varepsilon}_{p}\right)$ is

$$
\begin{aligned}
\mathbb{V}\left(L_{t}(h), \varepsilon_{p, t}\right) \approx & \overline{\mathbb{V}}+\overline{\mathbb{V}}_{\bar{L}} \bar{L}\left(\hat{l}_{t}(h)+\frac{1}{2} \hat{l}_{t}^{2}(h)\right)+\overline{\mathbb{V}}_{\bar{\varepsilon}_{p}} \bar{\varepsilon}_{p}\left(\hat{\varepsilon}_{p, t}+\frac{1}{2}\left(\hat{\varepsilon}_{p, t}\right)^{2}\right) \\
& +\frac{1}{2} \overline{\mathbb{V}}_{\bar{L} \bar{L}} \bar{L}^{2} \hat{l}_{t}^{2}(h)+\frac{1}{2} \overline{\mathbb{V}}_{\bar{\varepsilon}_{p} \bar{\varepsilon}_{p}} \bar{\varepsilon}_{p}^{2} \hat{\varepsilon}_{p, t}^{2}+\overline{\mathbb{V}}_{\bar{L} \bar{\varepsilon}_{p}} \bar{L}_{\bar{\varepsilon}_{p}}\left(\hat{l}_{t}(h) \hat{\varepsilon}_{p, t}\right) \\
& +\mathcal{O}\left(\|\zeta\|^{3}\right)
\end{aligned}
$$

with

$$
\begin{aligned}
& \overline{\mathbb{V}}_{\bar{L}}=\bar{\varepsilon}_{p} \bar{L}^{\varphi}, \\
& \overline{\mathbb{V}}_{\bar{\varepsilon}_{p}}=\frac{1}{1+\varphi}(\bar{L})^{1+\varphi}=\frac{\bar{L}}{(1+\varphi) \bar{\varepsilon}_{p}} \overline{\mathbb{V}}_{\bar{L}}, \\
& \overline{\mathbb{V}}_{\bar{L} \bar{L}}=\varphi \bar{\varepsilon}_{p} \bar{L}^{\varphi-1}=\frac{\varphi}{\bar{L}} \overline{\mathbb{V}}_{\bar{L}} \text {, } \\
& \overline{\mathbb{V}}_{\bar{\varepsilon}_{p} \bar{\varepsilon}_{p}}=0 \text {, } \\
& \overline{\mathbb{V}}_{\bar{L} \bar{\varepsilon}_{p}}=\bar{L}^{\varphi}=\frac{\overline{\mathbb{V}}_{\bar{L}}}{\bar{\varepsilon}_{p}} .
\end{aligned}
$$

The disutility of work becomes

$$
\begin{aligned}
\mathbb{V}\left(L_{t}(h), \varepsilon_{p, t}\right) \approx & \overline{\mathbb{V}}_{\bar{L}} \bar{L}\left\{\hat{l}_{t}(h)+\frac{1+\varphi}{2} \hat{l}_{t}^{2}(h)+\hat{l}_{t}(h) \hat{\varepsilon}_{p, t}\right\} \\
& + \text { t.i.p. }+\mathcal{O}\left(\|\zeta\|^{3}\right) .
\end{aligned}
$$


Individual Labor to Composite Labor

Now define the composite labor index:

$$
L_{t}=\int_{0}^{n} L_{t}(h) \mathrm{d} h=\int_{0}^{n} \frac{Y_{t}(h)}{\varepsilon_{a, t}} \mathrm{~d} h=\frac{Y_{t}}{\varepsilon_{a, t}} \int_{0}^{n}\left(\frac{\tilde{P}_{t}(h)}{P_{t}}\right)^{-\theta} \mathrm{d} h .
$$

Taking a second-order Taylor expansion of the logarithm of this equation yields

$$
\hat{l}_{t}=\hat{y}_{t}-\hat{\varepsilon}_{a, t}+\hat{u}_{t}
$$

where $\hat{u}_{t}=\ln \int_{0}^{n}\left(\frac{\tilde{P}_{t}(h)}{P_{t}}\right)^{-\theta} \mathrm{d} h$ is of second order. As shown by Woodford (2003, chap. 6), one has

$$
\hat{u}_{t}=\frac{\theta \alpha}{2(1-\alpha)(1-\beta \alpha)}\left(\hat{\pi}_{H, t}-\xi \hat{\pi}_{H, t-1}\right)^{2}+\mathcal{O}\left(\|\zeta\|^{3}\right) .
$$

\section{Welfare Expressions}

We first integrate equation (55) over $h$ and replace $\int_{0}^{n} L_{t}(h) \mathrm{d} h$ and $\hat{u}_{t}$ with their respective expressions. We then take the present discounted sum of equations (53) and (55) and subtract the second expression from the first one to obtain

$$
\begin{aligned}
\sum_{t=0}^{\infty} \beta^{t} \mathbb{W}_{t}= & \overline{\mathbb{U}}_{\bar{C}} \bar{C} \sum_{t=0}^{\infty} \beta^{t}\left\{\left(\hat{c}_{t}-\gamma \hat{c}_{t-1}\right)+\frac{1}{2}\left(\hat{c}_{t}^{2}-\gamma \hat{c}_{t-1}^{2}\right)\right. \\
& -\frac{\sigma}{2(1-\gamma)}\left(\hat{c}_{t}-\gamma \hat{c}_{t-1}\right)^{2}+\hat{c}_{t} \hat{\varepsilon}_{p, t}-\gamma \hat{c}_{t-1} \hat{\varepsilon}_{p, t}-s^{-1} \hat{y}_{t} \\
& -\frac{1+\varphi}{2 s}\left(\hat{y}_{t}-\hat{\varepsilon}_{a, t}\right)^{2}-s^{-1} \hat{y}_{t} \hat{\varepsilon}_{p, t}-\frac{\theta \alpha}{2(1-\alpha)(1-\beta \alpha) s} \\
& \left.\times\left(\hat{\pi}_{H, t}-\xi \hat{\pi}_{H, t-1}\right)^{2}\right\}+t . i . p .+\mathcal{O}\left(\|\zeta\|^{3}\right) .
\end{aligned}
$$

Recall that $\overline{\mathbb{V}}_{\bar{L}}=\overline{\mathbb{U}}_{\bar{C}}$ and $s=\bar{C} / \bar{Y}$. Given that

$$
\sum_{t=0}^{\infty} \beta^{t} x_{t-1}=x_{-1}+\beta \sum_{t=0}^{\infty} \beta^{t} x_{t}=\beta \sum_{t=0}^{\infty} \beta^{t} x_{t}+\text { t.i.p. }
$$


and using the fact that

$$
(1+\varphi) \hat{\varepsilon}_{a, t}=A_{1} \hat{c}_{t}^{n}+A_{2} \hat{c}_{t-1}^{n}+A_{3} \hat{c}_{t}^{* n}+A_{4} \hat{c}_{t-1}^{* n}+A_{5} \hat{\varepsilon}_{p, t}+A_{6} \hat{\varepsilon}_{p, t}^{*}
$$

where parameters $A_{j}(j=1, \cdots, 6)$ find their counterparts in equation (46), it yields

$$
\begin{aligned}
\mathcal{W}_{0}= & \mathbb{E}_{0} \sum_{t=0}^{\infty} \beta^{t} \mathbb{W}_{t}=-\overline{\mathbb{U}}_{\bar{C}} \bar{C} \mathbb{E}_{0} \sum_{t=0}^{\infty} \beta^{t}\left\{-(1-\beta \gamma) \hat{c}_{t}+s^{-1} \hat{y}_{t}\right. \\
& +\frac{\sigma}{2(1-\gamma)}\left(\hat{c}_{t}-\gamma \hat{c}_{t-1}\right)^{2}-\frac{(1-\beta \gamma)}{2} \hat{c}_{t}^{2}+\frac{1+\varphi}{2 s} \hat{y}_{t}^{2} \\
& +\left(\gamma \beta \rho_{p}-1\right) \hat{c}_{t} \hat{\varepsilon}_{p, t} \\
& -s^{-1}\left(A_{1} \hat{c}_{t}^{n}+A_{2} \hat{c}_{t-1}^{n}+A_{3} \hat{c}_{t}^{* n}+A_{4} \hat{c}_{t-1}^{* n}+A_{5} \hat{\varepsilon}_{p, t}+A_{6} \hat{\varepsilon}_{p, t}^{*}\right) \hat{y}_{t} \\
& \left.+s^{-1} \hat{y}_{t} \hat{\varepsilon}_{p, t}+\frac{\theta \alpha}{2(1-\alpha)(1-\beta \alpha) s}\left(\hat{\pi}_{H, t}-\xi \hat{\pi}_{H, t-1}\right)^{2}\right\} \\
& +t . i . p .+\mathcal{O}\left(\|\zeta\|^{3}\right) .
\end{aligned}
$$

Finally, replacing the cross-product $x_{1, t} x_{2, t}$ with $\left(x_{1, t}^{2}+x_{2, t}^{2}-\right.$ $\left.\left(x_{1, t}-x_{2, t}\right)^{2}\right) / 2$, we can rewrite the home welfare criterion as

$$
\begin{aligned}
\mathcal{W}_{0}= & -\frac{\bar{U}_{\bar{C}} \bar{C}}{2} \mathbb{E}_{0} \sum_{t=0}^{\infty} \beta^{t}\left\{\left(\hat{c}_{t}-\Psi_{c}\right)^{2}+\frac{\left(1+\hat{y}_{t}\right)^{2}}{s}\right. \\
& +\left(\beta \gamma\left(1+\rho_{p}\right)-3\right) \hat{c}_{t}^{2} \\
& +\frac{1+\varphi-A_{1}-A_{2}-A_{3}-A_{4}-A_{5}-A_{6}}{s} \hat{y}_{t}^{2} \\
& +\frac{\sigma}{(1-\gamma)}\left(\hat{c}_{t}-\gamma \hat{c}_{t-1}\right)^{2}-\left(\beta \gamma \rho_{p}-1\right)\left(\hat{c}_{t}-\hat{\varepsilon}_{p, t}\right)^{2} \\
& +\frac{A_{1}}{s}\left(\hat{y}_{t}-\hat{c}_{t}^{n}\right)^{2}+\frac{A_{2}}{s}\left(\hat{y}_{t}-\hat{c}_{t-1}^{n}\right)^{2}+\frac{A_{3}}{s}\left(\hat{y}_{t}-\hat{c}_{t}^{* n}\right)^{2} \\
& +\frac{A_{4}}{s}\left(\hat{y}_{t}-\hat{c}_{t-1}^{* n}\right)^{2}-\frac{1-A_{5}}{s}\left(\hat{y}_{t}-\hat{\varepsilon}_{p, t}\right)^{2}+\frac{A_{6}}{s}\left(\hat{y}_{t}-\hat{\varepsilon}_{p, t}^{*}\right)^{2} \\
& \left.+\frac{\theta \alpha}{(1-\alpha)(1-\beta \alpha) s}\left(\hat{\pi}_{H, t}-\xi \hat{\pi}_{H, t-1}\right)^{2}\right\}+t . i \cdot p .+\mathcal{O}\left(\|\eta\|^{3}\right),
\end{aligned}
$$

where $\Psi_{c}=(1-\beta \gamma)$. 
The calculations for the welfare of the foreign representative household yield

$$
\begin{aligned}
\mathcal{W}_{0}^{*}= & -\frac{\overline{\mathbb{U}}_{\bar{C}^{*}}^{*} \bar{C}^{*}}{2} \mathbb{E}_{0} \sum_{t=0}^{\infty} \beta^{t}\left\{\left(\hat{c}_{t}^{*}-\Psi_{c}^{*}\right)^{2}+\frac{\left(1+\hat{y}_{t}^{*}\right)^{2}}{s^{*}}\right. \\
& +\left(\beta \gamma^{*}\left(1+\rho_{p}^{*}\right)-3\right) \hat{c}_{t}^{* 2} \\
& +\frac{1+\varphi^{*}-A_{1}^{*}-A_{2}^{*}-A_{3}^{*}-A_{4}^{*}-A_{5}^{*}-A_{6}^{*} \hat{y}_{t}^{* 2}}{s^{*}} \\
& +\frac{\sigma^{*} \gamma^{*}}{\left(1-\gamma^{*}\right)}\left(\hat{c}_{t}^{*}-\gamma^{*} \hat{c}_{t-1}^{*}\right)^{2}-\left(\beta \gamma^{*} \rho_{p}^{*}-1\right)\left(\hat{c}_{t}^{*}-\hat{\varepsilon}_{p, t}^{*}\right)^{2} \\
& +\frac{A_{1}^{*}}{s^{*}}\left(\hat{y}_{t}^{*}-\hat{c}_{t}^{n}\right)^{2}+\frac{A_{2}^{*}}{s^{*}}\left(\hat{y}_{t}^{*}-\hat{c}_{t-1}^{n}\right)^{2}+\frac{A_{3}^{*}}{s^{*}}\left(\hat{y}_{t}^{*}-\hat{c}_{t}^{* n}\right)^{2} \\
& +\frac{A_{4}^{*}}{s^{*}}\left(\hat{y}_{t}^{*}-\hat{c}_{t-1}^{* n}\right)^{2}+\frac{A_{5}^{*}}{s^{*}}\left(\hat{y}_{t}^{*}-\hat{\varepsilon}_{p, t}\right)^{2}-\frac{1-A_{6}^{*}}{s^{*}}\left(\hat{y}_{t}^{*}-\hat{\varepsilon}_{p, t}^{*}\right)^{2} \\
& \left.+\frac{\theta \alpha^{*}}{\left(1-\alpha^{*}\right)\left(1-\beta \alpha^{*}\right) s^{*}}\left(\hat{\pi}_{F, t}^{*}-\xi^{*} \hat{\pi}_{F, t-1}^{*}\right)^{2}\right\}+t . i . p .+\mathcal{O}\left(\|\eta\|^{3}\right),
\end{aligned}
$$

where $\Psi_{c}^{*}=\left(1-\beta \gamma^{*}\right)$.

\section{References}

Abel, A. 1990. "Asset Prices under Habit Formation and Catching Up with the Joneses." American Economic Review 80 (2): 38-42. Aksoy, Y., P. De Grauwe, and H. Dewachter. 2002. "Do Asymmetries Matter for European Monetary Policy?" European Economic Review 46 (3): 443-69.

Altissimo, F., B. Mojon, and P. Zaffaroni. 2007. "Fast Micro and Slow Macro: Can Aggregation Explain the Persistence of Inflation?" ECB Working Paper No. 729.

Amato, J. D., and T. S. Laubach. 2004. "Implications of Habit Formation for Optimal Monetary Policy." Journal of Monetary Economics 51 (2): 305-25.

Angelini, P., P. Del Giovane, S. Siviero, and D. Terlizzese. 2002. "Monetary Policy Rules for the Euro Area: What Role for National Information?" Working Paper No. 457, Banca d'Italia. Benigno, G. 2004. "Real Exchange Rate Persistence and Monetary Policy Rules." Journal of Monetary Economics 51 (3): 473-502. 
Benigno, G., and P. Benigno. 2003. "Price Stability in Open Economies." Review of Economic Studies 70 (4): 743-64.

Benigno, P. 2004. "Optimal Monetary Policy in a Currency Area." Journal of International Economics 63 (2): 293-320.

Benigno, P., and J. D. López-Salido. 2006. "Inflation Persistence and Optimal Monetary Policy in the Euro Area." Journal of Money, Credit, and Banking 38 (3): 587-614.

Calvo, G. 1983. "Staggered Prices in a Utility-Maximizing Framework." Journal of Monetary Economics 12 (3): 383-98.

Chari, V. V., P. J. Kehoe, and E. R. McGrattan. 2002. "Can Sticky Price Models Generate Volatile and Persistent Real Exchange Rates?" Review of Economic Studies 69 (3): 533-63.

Christiano, L. J., M. Eichenbaum, and C. L. Evans. 2005. "Nominal Rigidities and the Dynamic Effects of a Shock to Monetary Policy." Journal of Political Economy 113 (1): 1-45.

Clarida, R., J. Galí, and M. Gertler. 2002. "A Simple Framework for International Monetary Policy Analysis." Journal of Monetary Economics 49 (5): 879-904.

Corsetti, G., and P. Pesenti. 2001. "Welfare and Macroeconomic Interdependence." Quarterly Journal of Economics 116 (2): 42146.

2005. "International Dimensions of Optimal Monetary Policy." Journal of Monetary Economics 52 (2): 281-305.

De Grauwe, P. 2000. "Monetary Policies in the Presence of Asymmetries." Journal of Common Market Studies 38 (4): 593-612.

De Grauwe, P., and T. Piskorski. 2001. "Union-Wide Aggregates versus National Data Based Monetary Policies: Does It Matter for the Eurosystem?" CEPR Discussion Paper No. 3036.

Demertzis, M., and A. Hughes Hallett. 1998. "Asymmetric Transmission Mechanisms and the Rise in European Unemployment: A Case of Structural Differences or of Policy Failures?" Journal of Economic Dynamics and Control 22 (6): 869-86.

Devereux, M. B., and C. Engel. 2003. "Monetary Policy in the Open Economy Revisited: Price Setting and Exchange-Rate Flexibility." Review of Economic Studies 70 (4): 765-83.

Dieppe, A., K. Küster, and P. McAdam. 2005. "Optimal Monetary Policy Rules for the Euro Area: An Analysis Using the Area Wide Model." Journal of Common Market Studies 43 (3): 507-37. 
Erceg, C. J., D. W. Henderson, and A. T. Levin. 2000. "Optimal Monetary Policy with Staggered Wage and Price Contracts." Journal of Monetary Economics 46 (2): 281-313.

Fagan, G., J. Henry, and R. Mestre. 2005. "An Area-Wide Model for the Euro Area." Economic Modelling 22 (1): 39-59.

Fernandez-Villaverde, J., and J. F. Rubio-Ramirez. 2004. "Comparing Dynamic Equilibrium Models to Data: A Bayesian Approach." Journal of Econometrics 123 (1): 153-87.

Galí, J., and T. Monacelli. 2005. "Monetary Policy and Exchange Rate Volatility in a Small Open Economy." Review of Economic Studies 72 (3): 707-34.

Geweke, J. 1999. "Computational Experiments and Reality." Manuscript, University of Minnesota and Federal Reserve Bank of Minneapolis.

Giannoni, M. P., and M. Woodford. 2005. "Optimal InflationTargeting Rules." In The Inflation Targeting Debate, ed. B. S. Bernanke and M. Woodford, 93-162. Chicago: University of Chicago Press.

Granger, C. W. J. 1980. "Long Memory Relationships and the Aggregation of Dynamic Models." Journal of Econometrics 14 (2): $227-38$.

Justiniano, A., and B. Preston. 2004. "Small Open Economy DSGE Models: Specification, Estimation and Model Fit." Working Paper. (Now circulated as "Monetary Policy and Uncertainty in an Empirical Small Open Economy Model." 2006.)

Monacelli, T. 2001. "New International Monetary Arrangements and the Exchange Rate." International Journal of Finance and Economics 6 (4): 389-400.

Monteforte, L., and S. Siviero. 2003. "Aggregate vs. Disaggregate Euro-Area Macro-Modelling." Manuscript, Banca d'Italia.

Obstfeld, M., and K. Rogoff. 1995. "Exchange Rate Dynamic Redux." Journal of Political Economy 103 (3): 624-60.

Onatski, A., and N. Williams. 2004. "Empirical and Policy Performance of a Forward-Looking Monetary Model." Manuscript, Columbia University.

Pytlarczyk, E. 2005. "An Estimated DSGE Model for the German Economy within the Euro Area." Deutsche Bundesbank Working Paper No. 33/2005. 
Rotemberg, J. J., and M. Woodford. 1998. "An Optimization-Based Econometric Framework for the Evaluation of Monetary Policy: Expanded Version." NBER Technical Working Paper No. 233.

Sbordone, A. M. 2003. "A Limited Information Approach to the Simultaneous Estimation of Wage and Price Dynamics." Manuscript, Rutgers University.

Schmitt-Grohé, S., and M. Uribe. 2004. "Optimal Operational Monetary Policy in the Christiano-Eichenbaum-Evans Model of the U.S. Business Cycle." Manuscript, Duke University.

Schorfheide, F. 2003. "Labor-Supply Shifts and Economic Fluctuations." Journal of Monetary Economics 50 (8): 1751-68.

Smets, F., and R. Wouters. 2002. "Openness, Imperfect Exchange Rate Pass-Through and Monetary Policy." Journal of Monetary Economy 49 (5): 947-81.

—. 2003. "An Estimated Dynamic Stochastic General Equilibrium Model of the Euro Area." Journal of the European Economic Association 1 (5): 1123-75.

Taylor, J. B. 1999. Monetary Policy Rules. Chicago: University of Chicago Press.

Tchakarov, I. 2004. "The Gains from International Monetary Cooperation Revisited." International Monetary Fund Working Paper No. 04/1.

Warnock, F. E. 2000. "Idiosyncratic Tastes in a Two-Country Optimizing Model: Implications of a Standard Assumption." International Finance Discussion Paper No. 631, Board of Governors of the Federal Reserve System.

Woodford, M. 2003. Interest and Prices: Foundations of a Theory of Monetary Policy. Princeton, NJ: Princeton University Press. 